Corrected: Publisher Correction

ARTICLE

https://doi.org/10.1038/s42003-019-0694-x OPEN

\title{
Endogenous formaldehyde is a memory-related molecule in mice and humans
}

Li Ai ${ }^{1,11}$, Tao Tan (10) 2,3,11, Yonghe Tang 4,11, Jun Yang 5,6, Dehua Cui ${ }^{5,6}$, Rui Wang ${ }^{5,6}$, Aibo Wang ${ }^{5,6}$, Xuechao Fei ${ }^{1}$, Yalan $\mathrm{Di}^{1}$, Xiaoming Wang ${ }^{1}$, Yan $\mathrm{Yu}^{7}$, Shengjie Zhao ${ }^{7}$, Weishan Wang ${ }^{4}$, Shangying Bai ${ }^{1,8}, \mathrm{Xu}$ Yang $\mathbb{1 0}^{9}$, Rongqiao He $\mathrm{H}^{1,10}$, Weiying Lin ${ }^{4,12}$, Hongbin $\mathrm{Han}^{5,6,12}$, Xiang Cai ${ }^{8,12} \&$ Zhiqian Tong ${ }^{1 \star}$

Gaseous formaldehyde is an organic small molecule formed in the early stages of earth's evolution. Although toxic in high concentrations, formaldehyde plays an important role in cellular metabolism and, unexpectedly, is found even in the healthy brain. However, its pathophysiological functions in the brain are unknown. Here, we report that under physiological conditions, spatial learning activity elicits rapid formaldehyde generation from mitochondrial sarcosine dehydrogenase (SARDH). We find that elevated formaldehyde levels facilitate spatial memory formation by enhancing $\mathrm{N}$-methyl-D-aspartate (NMDA) currents via the C232 residue of the NMDA receptor, but that high formaldehyde concentrations gradually inactivate the receptor by cross-linking NR1 subunits to NR2B. We also report that in mice with aldehyde dehydrogenase-2 (ALDH2) knockout, formaldehyde accumulation due to hypofunctional ALDH2 impairs memory, consistent with observations of Alzheimer's disease patients. We also find that formaldehyde deficiency caused by mutation of the mitochondrial SARDH gene in children with sarcosinemia or in mice with Sardh deletion leads to cognitive deficits. Hence, we conclude that endogenous formaldehyde regulates learning and memory via the NMDA receptor.

\footnotetext{
${ }^{1}$ Alzheimer's Disease Center, Beijing Institute for Brain Disorders; Center for Brain Disorders Research, Capital Medical University, Beijing 100069, China. ${ }^{2}$ Department of Physiology and Biophysics School of Medicine \& Biomedical Sciences, State University of New York at Buffalo, Buffalo, NY 14214, USA.

${ }^{3}$ Sichuan Provincial Hospital for Women and Children, Chengdu 610000, China. ${ }^{4}$ Institute of Fluorescent Probes for Biological Imaging, School of Chemistry and Chemical Engineering, School of Materials Science and Engineering, University of Jinan, Shandong 250022, China. ${ }^{5}$ Department of Radiology, Peking University Third Hospital, Beijing, China. ${ }^{6}$ Key Laboratory of Magnetic Resonance Imaging Equipment and Technique, Beijing 100191, China. ${ }^{7}$ Beijing Boai Hospital, China Rehabilitation Research Center, Beijing 100068, China. ${ }^{8}$ Department of Physiology, Southern Illinois University School of Medicine, Carbondale, IL 62901, USA. ${ }^{9}$ Section of Environmental Biomedicine, Hubei Key Laboratory of Genetic Regulation and Integrative Biology, College of Life Sciences, Central China Normal University, Wuhan 430079, China. ${ }^{10}$ State Key Laboratory of Brain \& Cognitive Science, Institute of Biophysics, CAS Key Laboratory of Mental Health, University of Chinese Academy of Sciences (UCAS), Beijing 100101, China. ${ }^{11}$ These authors equally contributed to this work: Li Ai, Tao Tan, Yonghe Tang. ${ }^{12}$ These authors jointly supervised this work: Weiying Lin, Hongbin Han, Xiang Cai. *email: tzqbeida@ccmu.edu.cn
} 
G aseous formaldehyde ( $\mathrm{MW}=30$ ) is one of the earliest organic molecules containing $\mathrm{C}, \mathrm{H}$, and $\mathrm{O}$ elements in the earth's early evolution ${ }^{1,2}$. Actually, formaldehyde is the primary precursor for most complex organic compounds, including amino acids, RNA, DNA, and proteins ${ }^{3}$. It is notoriously known as an indoor air pollutant that induces memory deficits in animals ${ }^{4}$, and cognitive decline in humans ${ }^{5}$. Formaldehyde is also present in every vertebrate cell as a possible byproduct of several metabolic reactions (e.g., methanol oxidation, DNA or histone demethylation $)^{6}$. Further, relatively high formaldehyde concentrations $(\sim 300 \mu \mathrm{M}$, which is 41,000 -fold lower than $37 \%$ Formalin contain: $1.23 \times 10^{7} \mu \mathrm{M}$ formaldehyde) have been detected in the brains of healthy adult mice, rats, and humans ${ }^{7,8}$, but it is unclear whether this is endogenous or from environmental contamination. Several recent studies suggested that formaldehyde may partially affect the activities of the $\mathrm{N}$ methyl-D-aspartate (NMDA)-type glutamate receptor (NMDA-R, consisting of the NR1 subunit and an NR2 or NR3 subunit) ${ }^{9,10}$. Notably, NMDA-R is widely believed to be critical for learning and memory by triggering associative synaptic plasticity ${ }^{11}$, suggesting a possible mechanism for formaldehyde-dependent cognitive modulations. However, whether endogenous formaldehyde affects cognitive activity through this or other pathways remains largely unknown.

Alzheimer's disease (AD) is a common neurodegenerative disease in the elderly characterized by persistent cognitive decline that has also been linked to disrupted formaldehyde metabolism $^{8,12}$. Polymorphism in mitochondrial aldehyde dehydrogenase $2(A L D H 2)$, which degrades formaldehyde, is a major risk factor for late-onset $\mathrm{AD}$ in the Chinese population ${ }^{13}$. In fact, $A L D H 2$ mutation in type-II diabetic patients is closely related to cognitive decline $e^{14,15}$. Injection of formaldehyde at pathological concentration (over $300 \mu \mathrm{M}$ ) indeed directly induces spatial memory deficits in healthy adult mice ${ }^{7,8}$. These findings suggest that $A L D H 2$ mutation-related endogenous formaldehyde overload may contribute to cognitive disorders in $\mathrm{AD}$.

Sarcosinemia is a rare pediatric neurodegenerative disease characterized by high levels of sarcosine in the blood and urine ${ }^{16}$, mental retardation (low intelligence quotient, intelligence quotient), speech disorder, and ataxia ${ }^{17}$. It is a recessive inherited disease linked to loss-of-function mutations in the sarcosine dehydrogenase gene $(S A R D H)$, resulting in $\sim 4$-fold reduced SARDH activity in the mitochondria. SARDH produces free formaldehyde in the conversion of sarcosine to glycine ${ }^{18}$, raising the possibility that the cognitive deficits of sarcosinemia are associated with brain formaldehyde deficiency.

In this study, we addressed the relationship between formaldehyde metabolism and cognitive disorders in children with sarcosinemia, $\mathrm{AD}$ dementia patients, and mice deficient in either SARDH $\left(\mathrm{Sardh}^{-1-}\right)$ or ALDH2 (Aldh2 $\left.{ }^{-1-}\right)$. The possible molecular mechanisms of formaldehyde-regulated NMDA-R activity via NR1 and/or NR2B subunits were also investigated. Our findings suggest that endogenous formaldehyde bidirectionally modulates cognition via NMDA-R, with both insufficiency and overabundance resulting in cognitive deficits.

\section{Results}

Learning activity induces rapid generation of formaldehyde. To investigate the role of brain formaldehyde in cognitive processes, we examined whether hippocampal formaldehyde concentration changes after spatial learning activity in Morris water maze (MWM) in the wild-type adult male Sprague-Dawley (SD) rats. First, we observed that healthy rats exhibited a rapid reduction in escape latency during training and significantly greater time spent in the target quadrant compared to nontarget quadrants during the probe test (Fig. 1a, b), suggesting that a classical spatial memory was forming in these rats. Notably, this spatial learning was associated with a marked increase in hippocampal formaldehyde as detected using a free formaldehyde-sensitive fluorescent probe $\mathrm{NaFA}^{19}$ (Fig. 1c). The magnitude of this elevation was $\sim 30 \mu \mathrm{M}$ on day 1 and $\sim 50 \mu \mathrm{M}$ on day 6 as quantified by high-performance liquid chromatography using a fluorescence detector (Fluo-HPLC) ${ }^{20}$ (Fig. 1d). These data strongly suggest that hippocampus-related spatial learning activity elicits an elevation in hippocampal formaldehyde levels.

Long-term potentiation (LTP) is considered a critical synaptoplastic mechanism underlying hippocampal learning and memory $^{21}$, so we examined the changes in formaldehyde levels during hippocampal LTP induction in healthy rats. Late-phase LTP was induced by stimulating the Schaffer collateral pathway with three trains of high-frequency electrical stimulation (HFS, $100 \mathrm{~Hz}, 20$ pulses) at 5-min intervals and recorded field excitatory postsynaptic potentials (fEPSPs) in the CA1 stratum radiatum in vivo (Fig. 1e). L-LTP was maintained for at least $2 \mathrm{~h}$ (fEPSP peak at 35 min after HFS (fold of baseline): $1.97 \pm 0.09$; fEPSP peak at 150 min after HFS: $1.29 \pm 0.04 ; n=10, p<0.01$ ) (Fig. 1f). Using the formaldehyde-sensitive fluorescent probe- NaFA to image formaldehyde intensity and Fluo-HPLC to quantify formaldehyde concentrations, we detected a marked increase $(\sim 50 \mu \mathrm{M})$ in hippocampal formaldehyde at $5 \mathrm{~min}$ post-HFS, which decreased over $1 \mathrm{~h}$ (Fig. $1 \mathrm{~g}, \mathrm{~h}$ ). These data indicate that formaldehyde generation mainly contributes to LTP induction.

Further, we investigated whether it is the excited hippocampal neurons that produce formaldehyde. One possible pathway is formaldehyde generation from the mitochondrial SARDH in the process of converting sarcosine to glycine ${ }^{18,22}$, while excess formaldehyde can be degraded by ALDH2 ${ }^{23}$ (Fig. 1i). Our results of using double-staining fluorescence histochemistry showed that SARDH was mainly colocalized with the mitochondrial marker-Cox IV (Fig. 1j). To further identify whether mitochondrial SARDH in the cultured hippocampal neurons contributes to formaldehyde generation, the competitive SARDH inhibitor- methoxyacetic acid was incubated before the excitatory neurotransmitter- glutamate (Glu) was added into the cultured medium. The results showed that Glu induced a marked decline in sarcosine levels concomitant with the rapid formaldehyde elevation $(\Delta \approx 30 \mu \mathrm{M})$. However, the mitochondrial SARDH inhibitor, methoxyacetic acid, suppressed sarcosine reduction and formaldehyde generation induced by Glu stimulation in vitro (Fig. $1 \mathrm{k}, \mathrm{l}$ ). These data confirm that this active formaldehyde generation is derived from mitochondrial SARDH.

To achieve real-time imaging this active formaldehyde generation in the synapse and soma of hippocampal neurons during the process of excitatory stimulation, a mitochondriasensitive formaldehyde fluorescence probe (mito-FA-probe, this probe is sensitive to both formaldehyde in the mitochondrial and mitochondrial membranes ${ }^{22}$ ) was added into the stimulating and recording electrodes which were patched in the soma of neurons (Fig. $1 \mathrm{~m}$ ). Then we recorded multiple action potentials in the postsynaptic neurons after given a train with 20 pulses of electrical stimulation in the presynaptic neurons in the cultured hippocampal neurons (Fig. $1 \mathrm{~m}$ ). The results showed that typical multiple action potentials were formed in postsynaptic neurons associated with a transient increase and then a rapid decrease in the fluorescence intensity of mito-FA-probe in the axons, especially in the synapses and somas of the pre- and postsynaptic neurons (Fig. 1n, o), indicating that electrical stimulation directly induces endogenous formaldehyde generation from the mitochondria and this elevated formaldehyde rapidly infuses into synaptic clefts from the activated mitochondria. The synapses, 

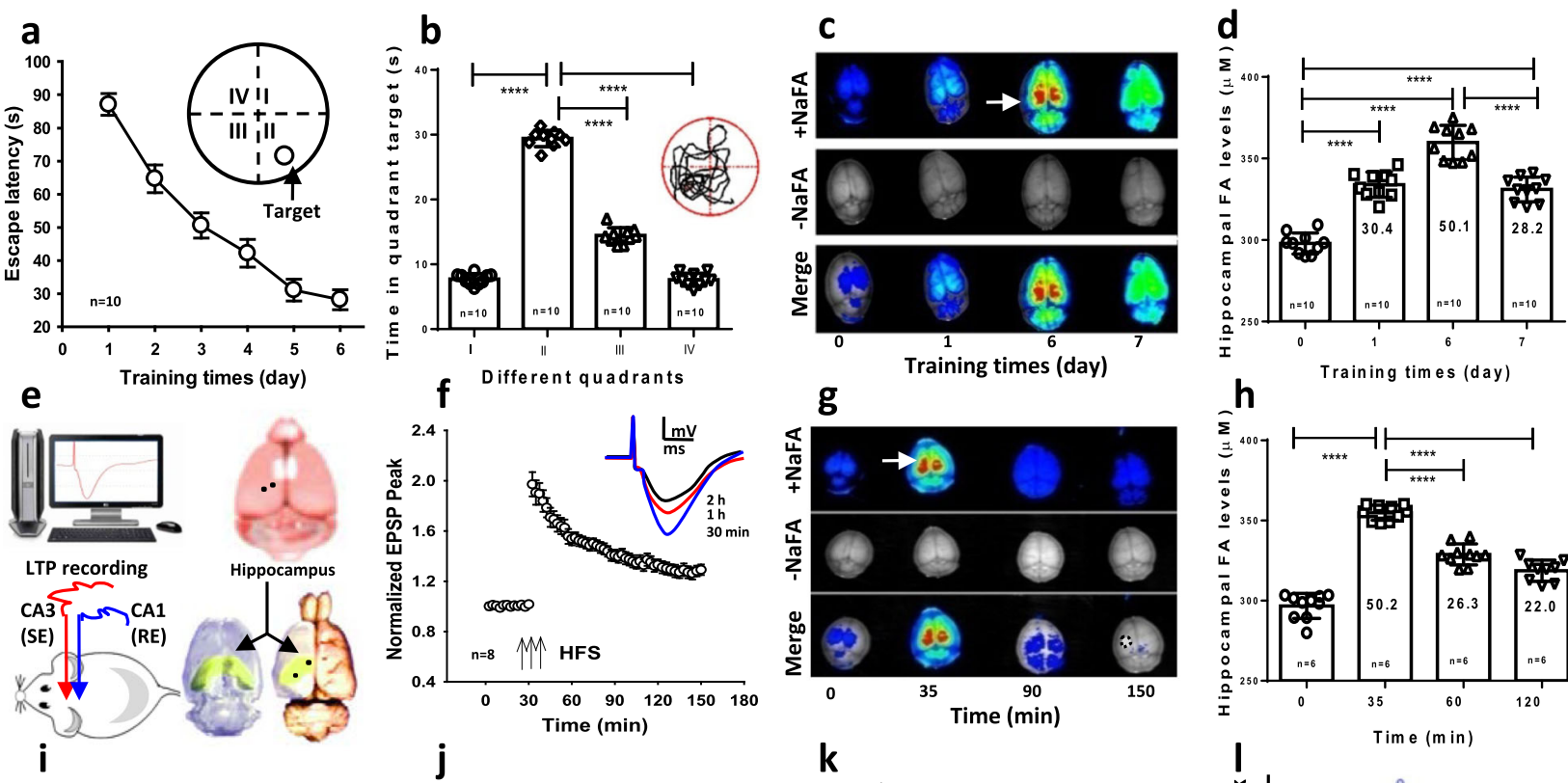

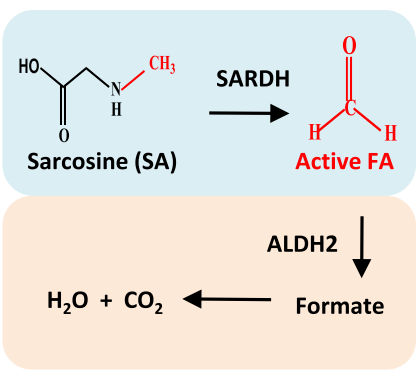

FA-metabolism pathway

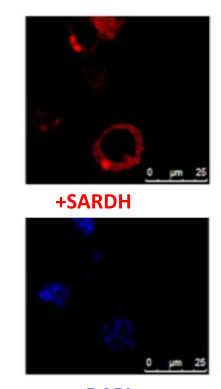

+DAPI

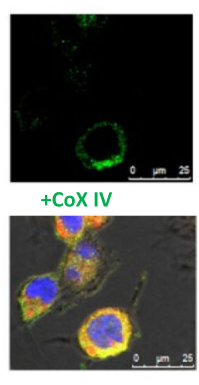

Merge
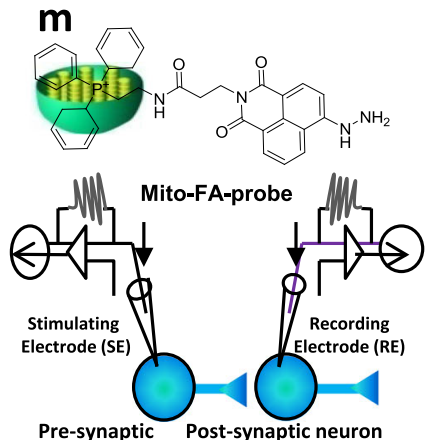

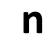

n

- Mito-FA-probe + Mito-FA-probe

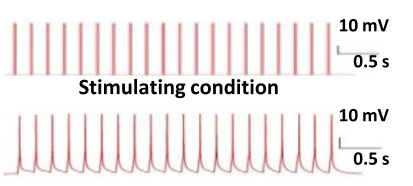

Recording action potentials

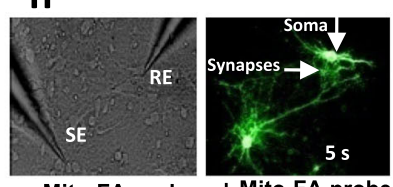

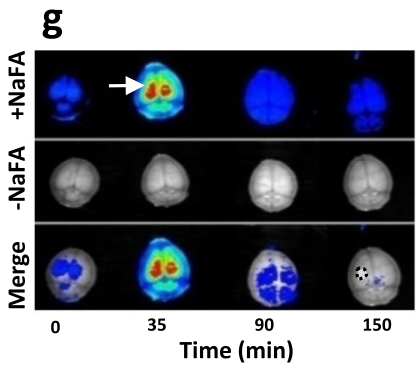

k
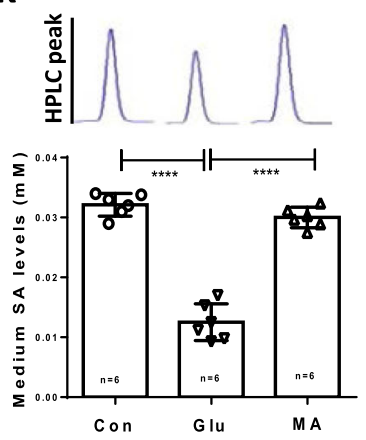

0

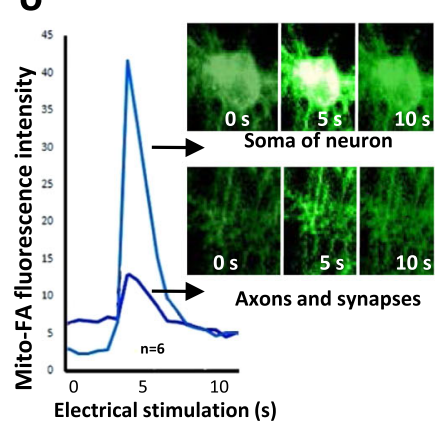

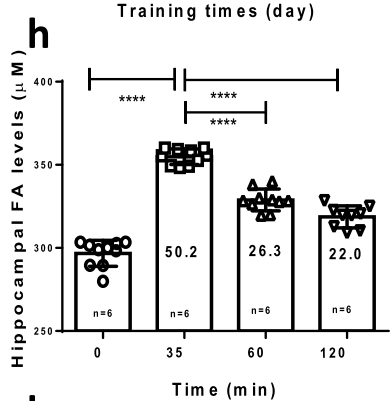

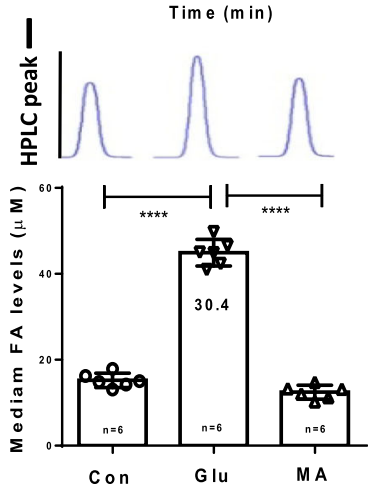

p

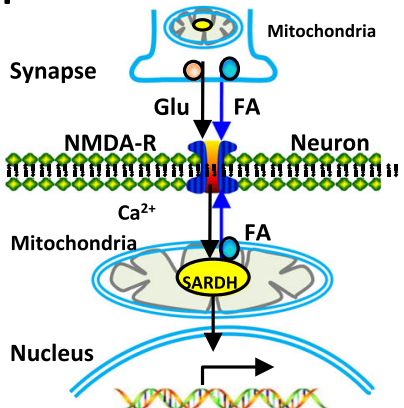

Fig. 1 Spatial learning elicits formaldehyde generation. a, b Spatial learning and memory in wild-type SD rats trained in the MWM ( $n=10$ per group). c Brain formaldehyde fluorescence revealed by the in vivo imaging system. NaFA: a fluorescence probe of free formaldehyde, $n=3$. d Hippocampal formaldehyde (FA) levels detected by Fluo-HPLC $(n=10)$. e An in vivo LTP recording in CA1 from Schaffer collateral stimulation and 3D views of the hippocampus (yellow). SE stimulating electrode, RE recording electrode. f Late-LTP (L-LTP) formation in vivo. $n=8$, HFS high-frequency stimulation. $\mathbf{g}$ Brain formaldehyde revealed by the in vivo imaging system, $n=3$. $\mathbf{h}$ Hippocampal formaldehyde levels detected by Fluo-HPLC ( $n=6$ ). $\mathbf{i}$ The pathway of formaldehyde metabolism. SARDH sarcosine dehydrogenase, ALDH2 aldehyde dehydrogenase. $\mathbf{j}$ Colocalization of SARDH (red) and the mitochondrial marker- Cox IV (green) in the cultured hippocampal neurons. DAPI: blue, a nuclear dye. k, I The cultured medium sarcosine and formaldehyde levels detected by Fluo-HPLC. SA sarcosine, MA methoxyacetic acid, an inhibitor of SARDH, $n=6$. $\mathbf{m}$ Intracellular infusion of the mitochondrial formaldehyde probe (mito-FA-probe). $\mathbf{n}$ A train of 20 pulses in the presynaptic neurons induced multiple action potentials in the postsynaptic neurons, $n=8$. 0 The active formaldehyde generated from mitochondria in the axon, synapse and soma of the cultured neurons imaged by the mito-FA probe, $n=6$. $\mathbf{p}$ The model of endogenous formaldehyde-enhanced memory formation. The data are expressed as the mean \pm standard error (s.e.m.). ${ }^{\star \star \star} p<0.001$; ${ }^{\star \star \star \star \star} p<0.0001$.

axons and somas of hippocampal neurons contain highly enriched mitochondria ${ }^{24,25}$, and formaldehyde may modulate NMDA-R activity ${ }^{9} 10$. Hence, we speculated that the mitochondrial SARDH-derived formaldehyde regulates memory formation via NMDA-R (Fig. 1p).
Formaldehyde precursors enhances LTP and memory formation. To examine whether this elevated active formaldehyde has effects on synaptic function and/or memory, formaldehyde precursors and aqueous formaldehyde solutions were directly intracerebroventricular injection (i.c.v.) or intrahippocampally 
a

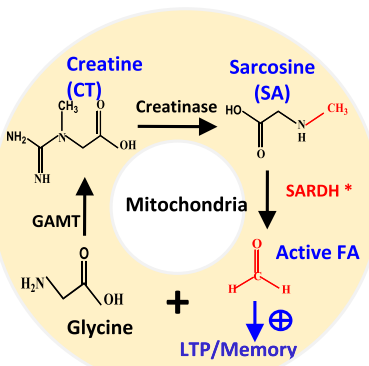

e

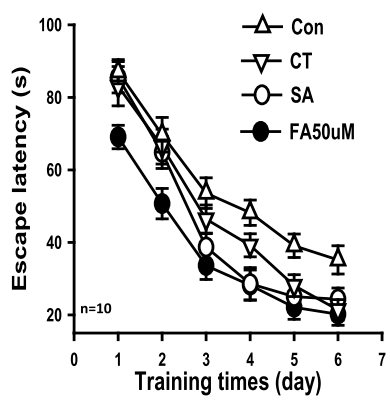

i

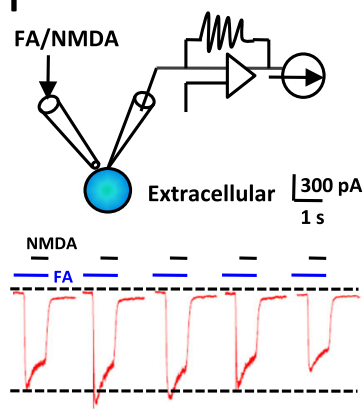

b

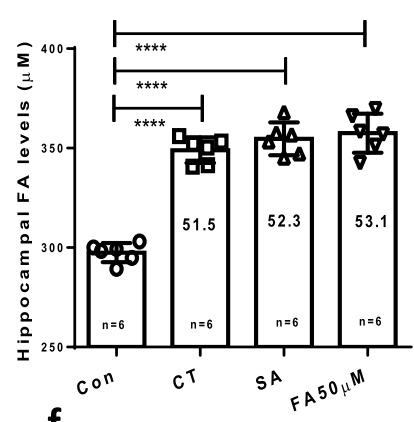

$f$

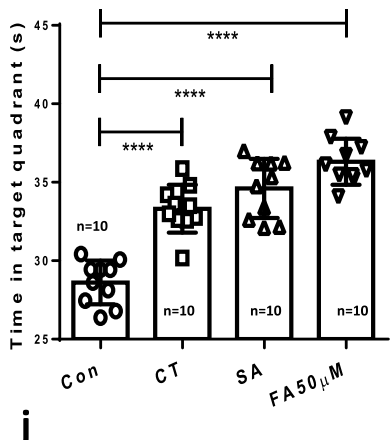

j

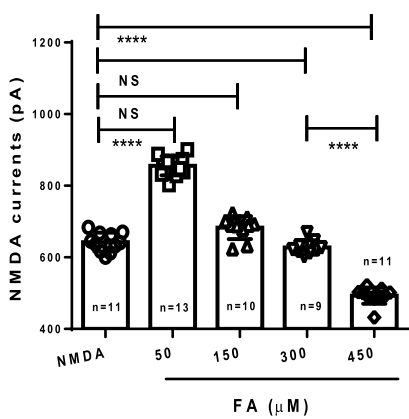

C
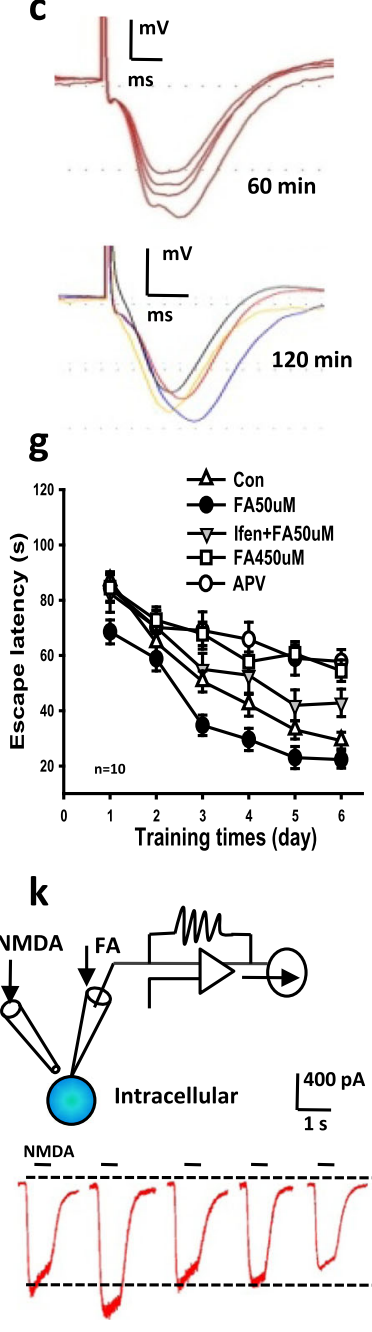

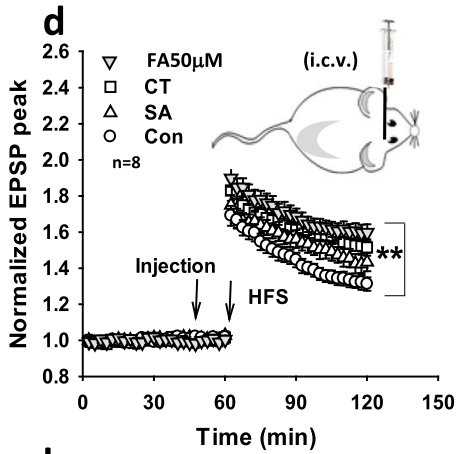

h

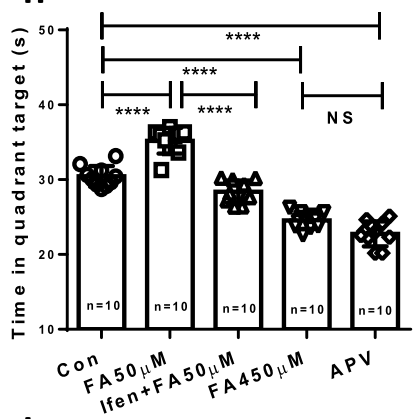

I

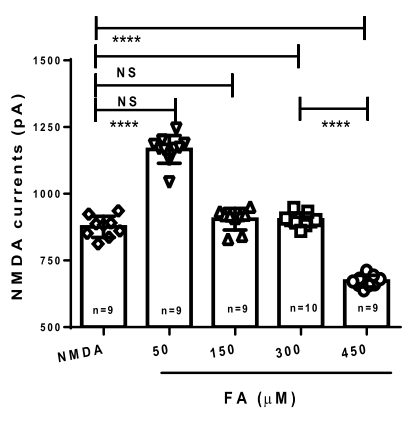

Fig. 2 Formaldehyde regulates LTP and memory via NMDA-R.a The metabolism pathway of formaldehyde precursors. GAMT guanidinoacetate methyltransferase, SARDH sarcosine dehydrogenase (a formaldehyde-generating enzyme), ALDH2 aldehyde dehydrogenase (a formaldehyde-degrading enzyme), FA formaldehyde, CT creatine, SA sarcosine. b Hippocampal formaldehyde levels quantified by HPLC-Fluo 30 min after i.c.v. injection with medicines-creatine $(200 \mu \mathrm{M})$, sarcosine $(200 \mu \mathrm{M})$, and formaldehyde $(50 \mu \mathrm{M})(n=6)$. c, d The fEPSP traces at 60 and 120 min (c) and enhancement of hippocampal long-term potentiation (LTP) (d) by infusion of above medicines $(n=8)$. e After 6 days of MWM training, repeated measures two-way ANOVA revealed a difference in group: $F_{(3,36)}=32.43, p<0.001$, time: $F_{(5,203)}=74.98, p<0.001$, and a group/time interaction: $F_{(15,203)}=6.32, p<$ 0.001. Post hoc tests showed that the mean escape latency values for the CT- and SA-injected group were significantly shorter than the control group on days 4, 5 and $6, t(36)=5.17, p<0.01$; and FA-injected group had shorter escape latency than the control group on days $1,2,3,4,5$ and $6, t(36)=7.11, p<$ 0.01 , respectively. $\mathbf{f}$ The CT-, SA-, and FA-injected mice had longer staying times in target quadrant than control (wild-type mice) ( $t(36)=9.29, p<0.001$, $n=10$ mice per group). $\mathbf{g}, \mathbf{h}$ The effects of Ifen and APV on spatial memory assayed by MWM ( $n=10$, rat per group). Ifenprodil (Ifen, $10 \mu M$, a specific antagonist of NR2B); DL-2-amino-5-phosphonovaleric acid (APV, $50 \mu \mathrm{M}$, a nonspecific antagonist of NMDA-R). i-I The effects of extracellular or intracellular infusion of various formaldehyde concentrations on NMDA currents in the cultured hippocampal neurons $(n=9-13)$. Data are expressed as the mean \pm standard error (s.e.m.). ${ }^{\star \star \star} p<0.001$; ${ }^{\star \star \star \star} p<0.0001$.

infused into the brains of healthy SD rats. Endogenous formaldehyde can be derived from foods, such as formaldehyde precursors: creatine and sarcosine. Creatine is transformed to sarcosine by creatinase ${ }^{26}$, and mitochondrial SARDH enzymolyzes sarcosine into active formaldehyde ${ }^{18,22}$ (Fig. 2a). After creatine, sarcosine, and formaldehyde $(50 \mu \mathrm{M})$ were intrahippocampally microinjected $30 \mathrm{~min}$, the hippocampi were taken out for detection of formaldehyde concentrations. We found that the elevated hippocampal formaldehyde levels were $\sim 50 \mu \mathrm{M}$ (Fig. 2b). To address whether these formaldehyde precursors enhance synaptic plasticity, we recorded hippocampal LTP in SD rats. The results showed that injection of creatine, sarcosine, and formaldehyde at $50 \mu \mathrm{M}$ (i.c.v. ${ }^{27}$ ) before HFS $30 \mathrm{~min}$ all facilitated LTP formation in vivo (65 min-fEPSP peak for Con: $1.352 \pm 0.037$;
fEPSP peak for formaldehyde: $1.667 \pm 0.0465$; fEPSP peak for creatine: $1.634 \pm 0.0508$; fEPSP peak for sarcosine: $1.505 \pm 0.045$. $\mathrm{F}_{(3,69)}=24.72 ; p<0.001$ ) (Fig. $2 \mathrm{c}, \mathrm{d}$ ). Scavenging this elevated formaldehyde suppresses in vivo LTP formation ${ }^{27}$. These data demonstrate that endogenous formaldehyde is required for LTP induction.

We further observed the effects of the intrahippocampal infusion of formaldehyde precursors on spatial memory in rats in MWM. Acquisition of the location of the hidden platform, measured as the average latency to find the platform over several sessions of training, each separated by a day. The formaldehyde-, sarcosine-, and creatine-injected rats demonstrated significantly rapider acquisition compared with control (Fig. 2e). On day 7 , the rats injected with creatine and sarcosine as well as formaldehyde 
treatment had longer times in target quadrant than control rats $(n=10, p<0.01)$ (Fig. 2f). Consequently, spatial learning activityrelated formaldehyde generation $(\Delta \sim 50 \mu \mathrm{M})$ contributes to the enhancement of LTP and memory formation.

Formaldehyde-regulated NMDA-R controls memory formation. The amino acid glutamate (Glu) is recognized to be the main excitatory neurotransmitter in the brains. Glu exerts excitotoxic activity by mainly activating NMDA-type glutamate receptor (NMDAR). This receptor has been the most extensively studied and the most frequently implicated in central nervous system diseases ${ }^{28}$. NMDA-R activity is critical for hippocampusdependent spatial memory ${ }^{11,29}$, and formaldehyde has been shown to modulate NMDA-R activity ${ }^{9,10}$; thus we hypothesized that antagonists of NMDA-R could have an effect of formaldehyde-associated spatial memory. After 6 days of MWM training, repeated measures two-way ANOVA revealed a difference in group: $\left(\mathrm{F}_{(4,20)}=37.09, p<0.001\right)$, training day $\left(\mathrm{F}_{(5,25)}=\right.$ $12.18, p<0.001)$, and a group $\times$ time interaction $\left(\mathrm{F}_{(20,100)}=6.45\right.$, $p<0.001)$. Post hoc tests showed that the mean escape latency values for excess formaldehyde-injected rats $(450 \mu \mathrm{M})$ were longer than control (wild-type rats) on day $3\left(\mathrm{~F}_{(4,20)}=5.12, p=\right.$ $0.003)$, day $4\left(\mathrm{~F}_{(4,20)}=6.24, p=0.001\right)$, day $5\left(\mathrm{~F}_{(4,20)}=7.15, p=\right.$ $0.003)$, and day $6\left(\mathrm{~F}_{(4,20)}=8.70, p=0.001\right)$; however, the rats injected with $50 \mu \mathrm{M}$ had shorter escape latency than control group on days $1,3,4,5$ and 6 , respectively $(p<0.001 ; n=10$, rat per group). Intrahippocampal injection of ifenprodil (Ifen, $10 \mu \mathrm{M}$, a specific antagonist of NR2B), statistically significant reduced 50 $\mu \mathrm{M}$ formaldehyde-enhanced spatial learning and memory in SD rats (Fig. 2g, h). Meanwhile, we also observed that intrahippocampally infusion of DL-2-amino-5-phosphonovaleric acid (APV, $50 \mu \mathrm{M}$, a nonspecific antagonist of NMDA-R) as well as $450 \mu \mathrm{M}$ formaldehyde injection did impair learning and memory in SD rats $(p<0.01$, Fig. 2 g, h). These data suggest that exogenous formaldehyde most likely affects memory via NMDA-R.

We then investigated whether exogenous and aqueous formaldehyde directly modulates NMDA currents in the cultured hippocampal neurons. As expected, both intracellular and extracellular infusion of formaldehyde at the active level (50 $\mu \mathrm{M}$ ) enhanced NMDAR-mediated currents, while 150-300 $\mu \mathrm{M}$ formaldehyde had no effect. Notably, a higher concentration (450 $\mu \mathrm{M}$ ) of formaldehyde inhibited NMDA- currents (Fig. 2i-1). Hence, exogenous formaldehyde bidirectionally modulates NMDAR activity.

Formaldehyde dually regulates NR1/NR2B via cysteine residues. To address the possible molecular mechanisms that this elevated formaldehyde $(\sim 50 \mu \mathrm{M})$ regulates NMDA-R, we transfected GFP-NR1a and NR2B plasmids into Chinese hamster ovary cells $(\mathrm{CHO})$ and tested the intracellular $\mathrm{Ca}^{2+}$ influx $\left(\left[\mathrm{Ca}^{2+}\right] i\right)$ by laser scanning confocal microscopy (Supplementary Fig. 1a). The results showed that formaldehyde at $50 \mu \mathrm{M}$ alone did not evoke $\mathrm{Ca}^{2+}$ influx; however, it enhanced NMDA-evoked $\left[\mathrm{Ca}^{2+}\right] i$ elevation. The specific NR2B antagonist ifenprodil (Ifen) could suppress this enhancement (Supplementary Fig. 1b), suggesting that NR2B may be the target of formaldehyde at $50 \mu \mathrm{M}$. Previous studies have shown that the tyrosine (Y) 231 and cysteine (C) 232 residues of NR2B are the specific binding sites for Ifen (3-dimensional (3D) crystal structure of NR1/NR2B complex, PBD ID: 3QEL) ${ }^{30,31}$ (Fig. 3a, b and Supplementary Fig. 2a), and formaldehyde spontaneously have reaction with cysteine $(\mathrm{C})^{32}$ (Fig. 3c). We speculated that Ifen prevents formaldehyde-binding to $\mathrm{C} 232$, thereby blocking formaldehydedependent facilitation of NMDAR activity (Supplementary Fig. 2b, c). Therefore, deleting the $\sim 400$-amino acid of amino- terminal domain (ATD) containing C232 (Supplementary Fig. 2d, e), or creating a single point mutation (C232A) in NR2B (the DNA sequences of the plasmid of NR2B with C232A mutation were identified by gene sequencing, Supplementary Fig. 3), was performed to identify that $\mathrm{C} 232$ residue in the ATD sequence is the target site for reaction with formaldehyde. Clearly, deleting ATD sequence of NR2B (D-ATD) reduced formaldehydeinduced enhancement of NMDA currents in the $\mathrm{CHO}$ cells transfected with plasmid of GFP-NR1/NR2B-D-ATD (Fig. 3d, e). This result suggests that the target residue of formaldehydeactivated NMDA-R may be at the ATD region. Further, we mutated the 232 Cysteine (C232) to Alanine (C232A) in the ATD structure, and found that formaldehyde-induced enhancement of NMDA currents was markedly reduced in the CHO cells transfected with plasmid of GFP-NR1/NR2B-C232A $(p<0.01)$ (Fig. 3d, e). These two critical evidences indicate that this C232 residue in ATD sequence of NR2B is the target site of formaldehyde $(50 \mu \mathrm{M})$-enhancing NMDA currents.

Injection of formaldehyde over $450 \mu \mathrm{M}$ impairs spatial memory in healthy rats; we speculated that $450 \mu \mathrm{M}$ formaldehyde may close or inactivate NMDA-R. A previous study found that there is cross-linking between residue C79 of NR1 and 80 lysine (K80) of NR2A $\mathrm{A}^{33}$. Actually, the C79 residue of NR1 and K79 of NR2B is not directly connected in the 3D crystal structure of NR1/NR2B complex (PBD ID: 4PE5) ${ }^{34}$; however, the short distance $(<10 \AA)$ of these two residues is enough to be linked by some small molecules (Fig. 3f). Our above data showed that formaldehyde could affect NR1/NR2B activity, and formaldehyde at a sufficient concentration can act as a cross-linker between the residues of proteins: $\mathrm{C}-\mathrm{C}, \mathrm{C}-\mathrm{K}$ and $\mathrm{C}-\mathrm{Y}^{35,36}$. This is a reasonable speculation that formaldehyde at $450 \mu \mathrm{M}$ may close or suppress NMDA-R by cross-linking C79 of NR1 to K79 of NR2B (Fig. 3g and Supplementary Fig. 4). In fact, a single point mutation of NR1 C79S, NR2B K79S, and the combination of NR1 C79S/ NR2B K79S (the DNA sequences of these two plasmids were identified by gene sequencing, Supplementary Figs. 5 and 6) reversed formaldehyde-mediated inhibition of NMDA currents in the transfected $\mathrm{CHO}$ cells, respectively (Fig. $3 \mathrm{~h}$, i). These data confirm that excessive formaldehyde suppresses NMDA-R activity by cross-linking NR1 to NR2B residues.

Formaldehyde overload impairs memory in Aldh2 ${ }^{-/-}$mice. Our above data indicate that exogenous formaldehyde dually regulates memory via NMDA-R. To address the critical question whether endogenous formaldehyde also affects memory, we deleted Aldh2 gene to artificially induce formaldehyde accumulation in the brains of Aldh2 $2^{-1-}$ mice (Fig. 4a) and assessed the spatial memory behaviors in MWM. Analyses of escape latency within each training day revealed that these 7 -month-old Aldh2 $2^{-1-}$ mice had significantly longer escape latency than WT mice $(n=10, p<0.01)$, indicating a marked impairment in the ability of spatial learning (Fig. 4b). Moreover, Aldh $2^{-1-}$ mice exhibited an obvious decline in spatial recall in the probe test, and neurochemical analyses confirmed elevated formaldehyde (approached maximum $500 \mu \mathrm{M}$ ) compared to WT mice $(\sim 300 \mu \mathrm{M})$ (Fig. $4 \mathrm{c}, \mathrm{d})$. In addition, these Aldh $2^{-1-}$ mice also showed a decrease in exploratory activity toward a novel object compared to WT mice in the open-field novel object recognition (NOR) test (Supplementary Fig. 7).

Then we investigated whether intragastric administration of $500 \mu \mathrm{M}$ L-cysteine (L-cys, a formaldehyde scavenger ${ }^{20,21}$ ) reduces brain formaldehyde concentrations and rescues memory deficits in healthy adult wild-type rats. After 6 days of MWM training, repeated measures two-way ANOVA revealed a difference in group: $\left(\mathrm{F}_{(2,27)}=11.36, p<0.001\right)$, training day $\left(\mathrm{F}_{(5,152)}=43.78\right.$, $p<0.001)$, and a group $\times$ time interaction $\left(\mathrm{F}_{(10,152)}=8.54\right.$, 
a
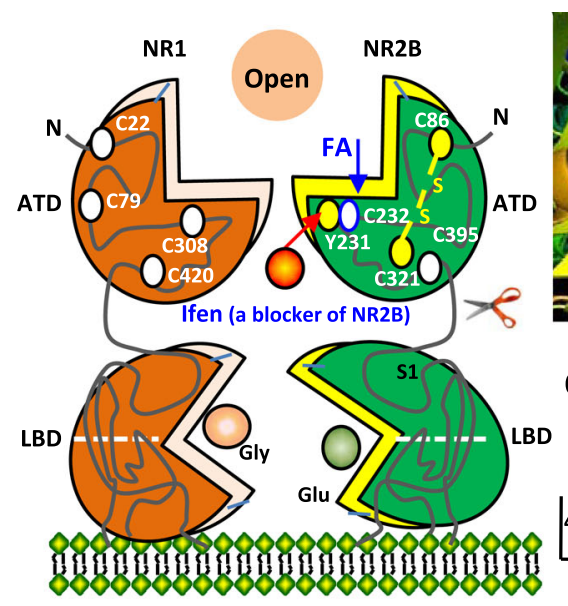

f
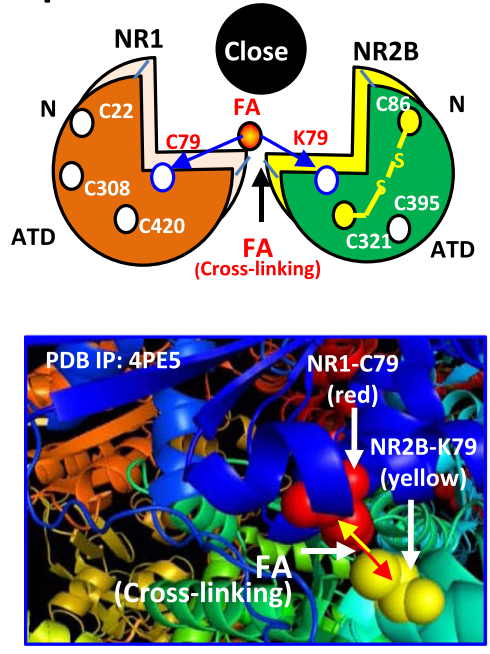

b

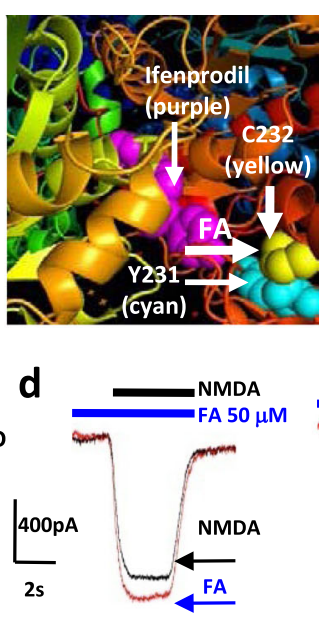

g
C

Reaction of L-cysteine/FA

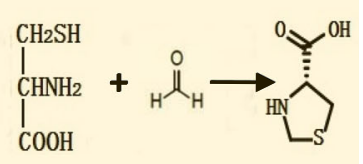

C FA Derivative

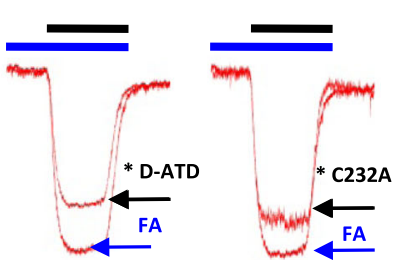

e

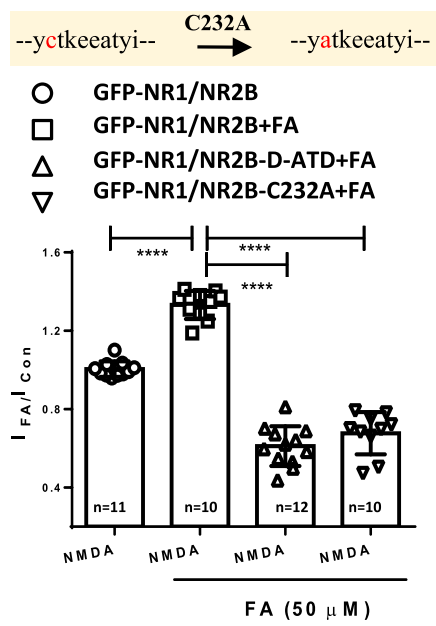

i

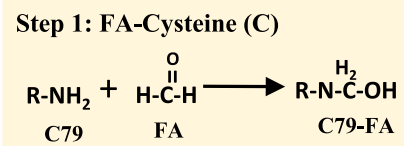

Step 2: FA crosslinks C-K residues $\underset{\mathrm{K} 79}{\mathrm{R}-\mathrm{N}-\mathrm{C}=\mathrm{H}_{2}} \stackrel{\stackrel{\mathrm{O}}{\|}}{\mathrm{H}_{2} \mathrm{~N}-\mathrm{C}-\mathrm{R}} \underset{\mathrm{C} 79-\mathrm{FA}}{\longrightarrow} \underset{\mathrm{H}-\mathrm{N}-\mathrm{C}-\mathrm{N}-\mathrm{C}_{\mathrm{H}}^{\stackrel{\mathrm{H}}{\mathrm{H}}}}{\longrightarrow}$

h

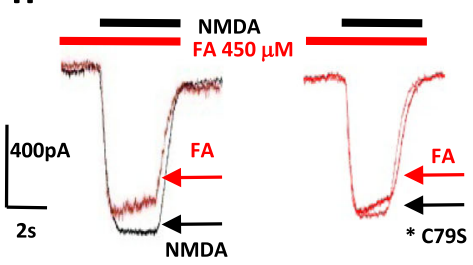

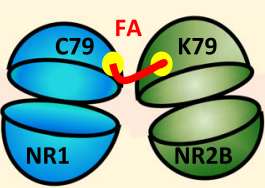

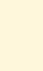

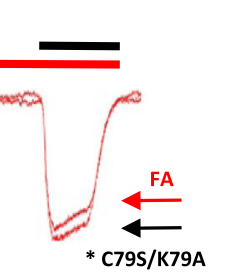

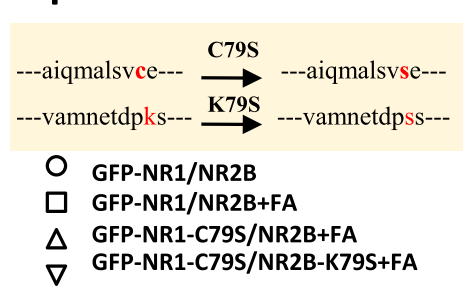

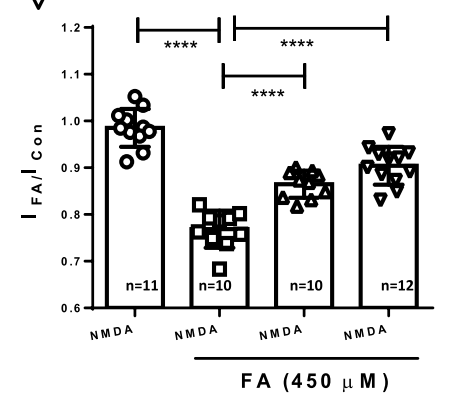

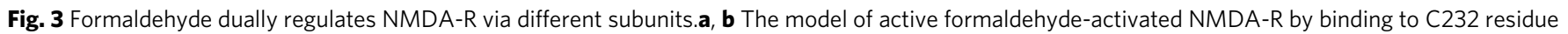

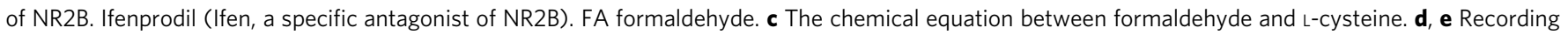
of NMDA currents in CHO cells cotransfected with GFP-NR1a and NR2B without the amino terminal domain (NR2B-ATD) or a single point mutation

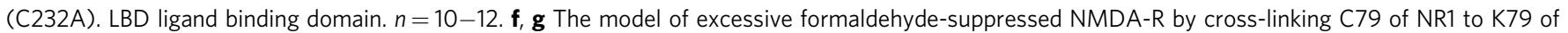

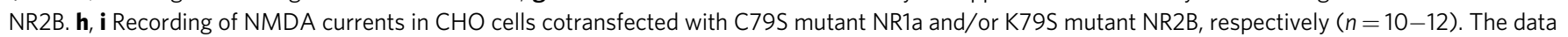
are expressed as the mean \pm standard error (s.e.m.). ${ }^{\star \star \star} p<0.001 ;{ }^{\star \star \star \star} p<0.0001$.

$p<0.001)$. Post hoc tests showed that the mean escape latency values for formaldehyde-injected rats were a significant longer than control (wild-type rats) on day $2\left(\mathrm{~F}_{(2,27)}=2.15, p=0.001\right)$, day $3\left(\mathrm{~F}_{(2,27)}=3.22, p=0.003\right.$, day $4\left(\mathrm{~F}_{(2,27)}=6.25, p=0.001\right)$, day $5\left(\mathrm{~F}_{(2,27)}=5.72, p=0.002\right)$, and day $6\left(\mathrm{~F}_{(2,27)}=6.07, p=\right.$ 0.001 ); while the escape latency in these rats injected with formaldehyde and L-cys was shorter than formaldehyde-injected rats on days 4,5 and 6 ( $p<0.01 ; n=10$ rat per group) (Fig. 4e). Treatment of L-cys for consecutive 7 days reversed excess formaldehyde injection-induced formaldehyde overload and memory impairments in healthy SD rats (Fig. $4 \mathrm{f}, \mathrm{g}$ ). These data confirm that endogenous formaldehyde overload directly causes memory decline in rats.

Formaldehyde is overloaded in AD patients. Our previous study showed that urine formaldehyde levels were negatively correlated with cognitive function in $\mathrm{AD}$ patients ${ }^{8}$. To establish the relationship between formaldehyde metabolism and ALDH2 activity (a formaldehyde-degrading enzyme) or cognitive decline, the cognitive abilities of 158 participants were examined using the Mini-Mental State Examination $\left(\mathrm{MMSE}^{8}\right)$ together with analysis of the genotype of $A L D H 2$ and urinalysis of formaldehyde (Supplementary Table 1). Consistent with a formaldehyde overload causing cognitive impairment, urine formaldehyde levels were negatively correlated with MMSE scores (Fig. 4h). Further, the activity of ALDH2 was about fivefold lower in the blood of AD patients than age-matched healthy controls (Fig. 4i), and magnetic resonance imaging (MRI) revealed marked atrophy in the left prefrontal lobe and significant ventriculomegaly (marked white triangle) compared to healthy controls (Fig. 4j, k). Genotype analysis by PCR showed that these patients harbored three genotypes of the $A L D H 2$ G487A variant: normal or typical homozygote $A L D H 2^{1^{*} 1}(\mathrm{GG})$, heterozygote $A L D H 2^{1^{* 2}}(\mathrm{GA})$, and homozygous mutant $A L D H 2^{2 * 2}$ (AA). Genotype distribution was consistent with Hardy-Weinberg equilibrium (Supplementary Table 2). In fact, $\mathrm{h} A L D H 2^{2 * 2}$ (AA) mutation has been found to induce ALDH2 inactivity ${ }^{14}$. Thus, combined with above results of 
a
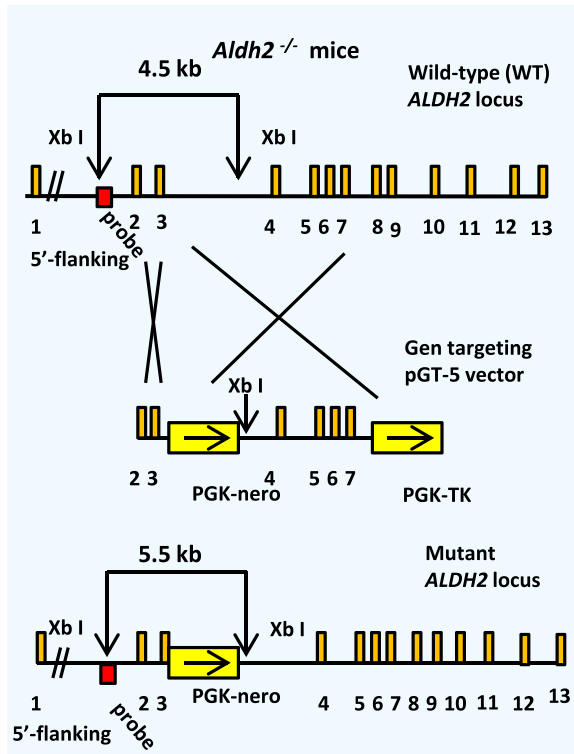

b
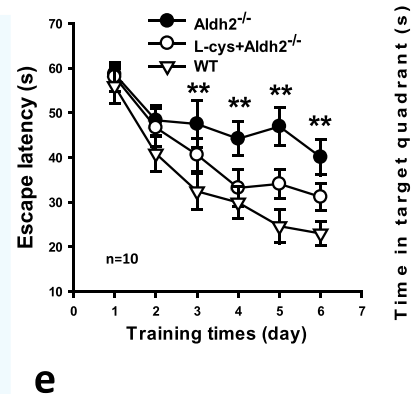

C

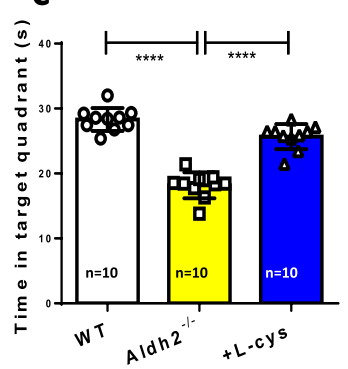

$f$

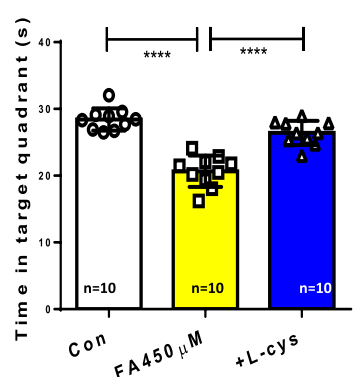

d
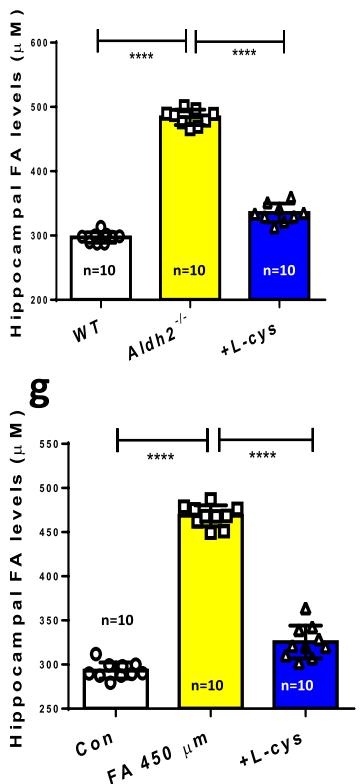

h

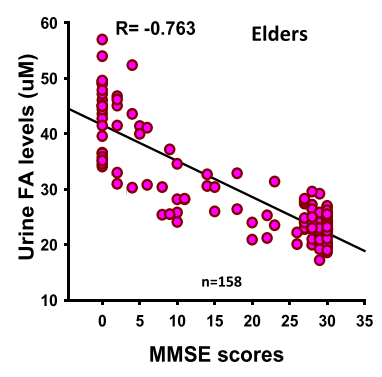

i

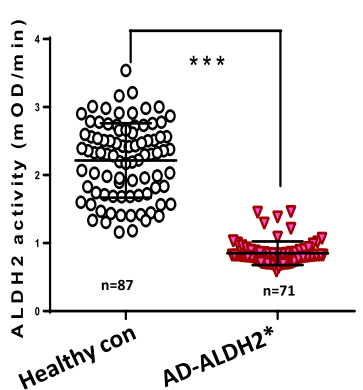

j
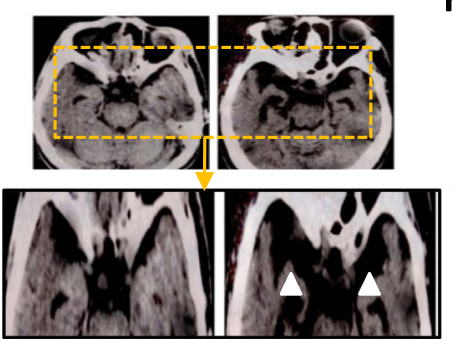

AD-ALDH2* $k$
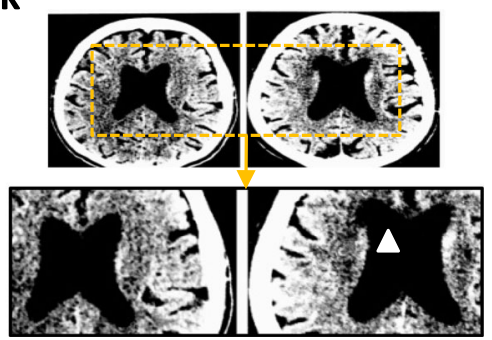

Healthy con

AD-ALDH2*

Fig. 4 ALDH2 mutation-induced formaldehyde overload causes amnesia.a The scheme for generation of Aldh2-/- mice. b After 6 days of MWM training, repeated measures two-way ANOVA revealed a difference in group: $\left(F_{(2,27)}=14.19, p<0.001\right)$, training time $\left(F_{(5,152)}=58.32, p<0.001\right)$, and a group $\times$ time interaction $\left(F_{(10,152)}=4.91, p<0.001\right)$. Post hoc tests showed that the mean escape latency values for $A L D H 2^{-} /-$mice were a significant longer than control (wild-type mice) on day $3\left(F_{(2,27)}=3.86, p=0.005\right)$, day $4\left(F_{(2,27)}=4.61, p=0.004\right)$, day $5\left(F_{(2,27)}=7.13, p=0.002\right)$, and day $6\left(F_{(2,27)}=\right.$ $6.27, p=0.001)$; while the escape latency in $A L D H 2^{-/}$mice with L-cys treatment was no statistically significant difference than control from days 1 to 5 ( $p>0.05 ; n=10$ mice per group). c $A L D H 2^{-/-}$mice with L-cys injection reversed the reduced time in target quadrant of these mutated mice without formaldehyde treatment $(t(27)=6.25, p<0.001)$. d Hippocampal formaldehyde (FA) concentrations detected by Fluo-HPLC ( $n=10)$. e, f Spatial learning and memory assayed by the MWM in WT rats with or without intrahippocampal infusion of excessive $(450 \mu \mathrm{M} ; t(27)=11.60, p=0.002)$ formaldehyde or formaldehyde scavenger-L-cysteine (L-cys: $500 \mu \mathrm{M})(t(27)=1.49, p=0.165) ; n=10$ mice/group). $\mathbf{g}$ Hippocampal formaldehyde levels detected by Fluo-HPLC $(n=10)$. h Negative relationship between urine formaldehyde and MMSE scores in 158 elderly AD patients. $\mathbf{i}$ ALDH2 activity analyzed by a human ALDH2 kit $(p<0.01)$. j Prefrontal lobe atrophy revealed by MRI. $\mathbf{k}$ Ventriculomegaly in AD patients with ALDH2 mutation. The data are expressed as the mean \pm standard error (s.e.m.). ${ }^{\star \star \star} p<0.001 ;{ }^{\star \star \star \star} p<0.0001$.

Aldh2-1- mice, hALDH2 with low-activity variants or loss-offunction mutations lead to formaldehyde overload and dementia in $\mathrm{AD}$ patients.

We also observed the effects of formaldehyde at different concentrations on cell viability in the cultured human SY5Y cells. The results showed that formaldehyde at $50 \mu \mathrm{M}$ enhanced cell viability, while formaldehyde at 150 and $300 \mu \mathrm{M}$ had no effect. However, 6-h formaldehyde incubation at $450 \mu \mathrm{M}$ clearly reduced cell viability (Supplementary Fig. 8). This result indicates that excess formaldehyde induces neuron death which contributes to cortical atrophy.

Formaldehyde is deficient in sarcosinemia children. Endogenous formaldehyde overload caused dementia in patients; we further want to know whether endogenous formaldehyde deficiency also affects human cognition. To answer this question, we examined the relationship between formaldehyde deficiency and intelligence quotient in children with sarcosinemia, a rare pediatric disease associated with the mutation of SARDH (a formaldehyde-generating enzyme ${ }^{18}$ ) (Supplementary Table 3). Intelligence quotient was assessed in 11 pediatric sarcosinemia patients using the Wechsler Intelligence Scale for Children (WISC) ${ }^{37}$ together with urinalysis for formaldehyde and blood SARDH activity measures. The results revealed a positive correlation between cognitive ability and urine formaldehyde in these children (Fig. 5a). Further, sarcosinemia patients exhibited lower SARDH activity in blood and lower formaldehyde concentrations in urine than age-matched healthy controls (Fig. 5b, c). Highthroughput gene sequencing identified SARDH mutations at c.1553, c.1540 and c.860 (Supplementary Fig. 9). The results of magnetic resonance imaging (MRI) and Fluorine ${ }^{18}$-fluorodeoxyglucose positron emission tomography/computed tomography ( ${ }^{18}$ F-FDG PET/CT) revealed substantial hippocampal atrophy (Fig. 5d, e). This finding was consistent with previous reports that 
a

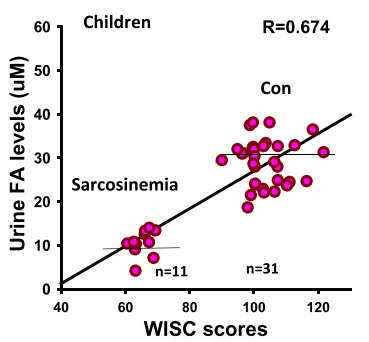

f

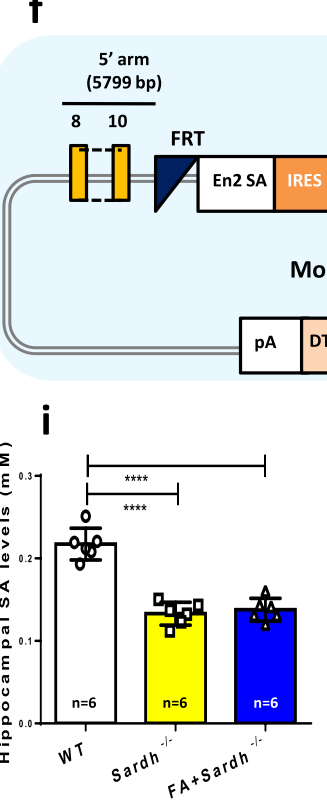

b

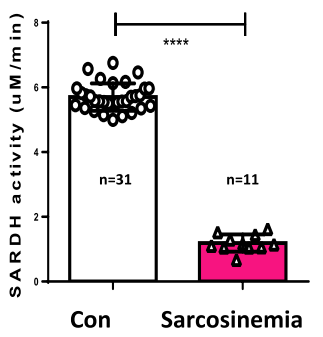

C

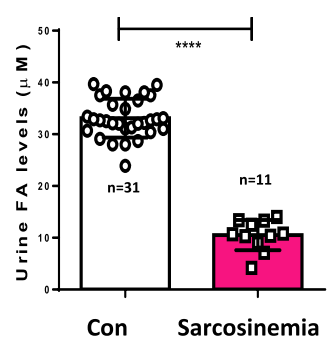

d

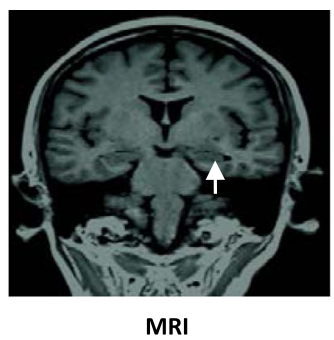

e

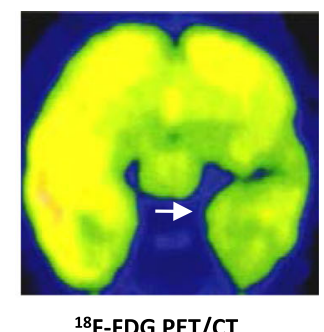

g
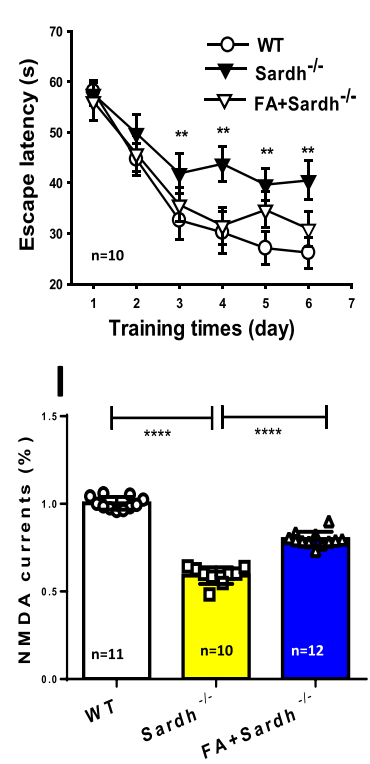

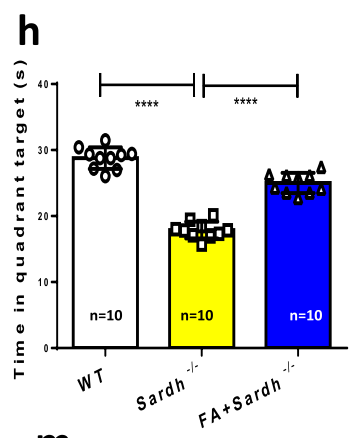

m

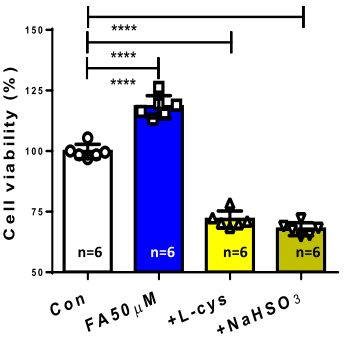

Fig. 5 SARDH mutation-induced formaldehyde deficiency causes amnesia.a Positive relationship between urine formaldehyde (FA) levels and Wechsler Intelligence Scale for Children (WISC) scores in 11 pediatric sarcosinemia patients and 31 healthy children. b Blood SARDH activity analyzed by a human SARDH kit $(p<0.01)$. c Urine formaldehyde concentrations detected by Fluo-HPLC $(p<0.01)$. d Right hippocampal atrophy revealed by MRI. e Impaired glucose metabolism in the right hippocampus revealed by ${ }^{18} \mathrm{~F}-\mathrm{FDG}$ PET/CT. $\mathbf{f}$ The scheme for generation of Sardh ${ }^{-/-}$mice. $\mathbf{g}$ After 6 days of MWM training, repeated measures two-way ANOVA revealed a difference in group: $\left(F_{(2,27)}=16.38, p<0.001\right)$, training time $\left(F_{(5,152)}=72.54, p<0.001\right)$, and a group $\times$ time interaction $\left(\mathrm{F}_{(10,152)}=2.45, p<0.001\right)$. Post hoc tests showed that the mean escape latency values for $S A R D H^{-1-}$ mice were a significant longer than control (wild-type mice) on day $3\left(F_{(2,27)}=2.41, p=0.001\right)$, day $4\left(F_{(2,27)}=4.57, p=0.005\right)$, day $5\left(F_{(2,27)}=6.39, p=0.003\right)$, and day 6 $\left(F_{(2,27)}=6.43, p=0.002\right)$; while there was no statistically significant difference in escape latency between $S A R D H^{-1}-$ mice with $200 \mu M$ formaldehyde injection and control ( $p>0.05 ; n=10$ mice per group). $\mathbf{h}$ SARDH ${ }^{-/}$mice with formaldehyde infusion reversed the reduced time in target quadrant of these mice without formaldehyde treatment $(p<0.001)$. i Hippocampal sarcosine levels detected by a mouse sarcosine kit, $n=6$. $\mathbf{j}$ Hippocampal formaldehyde levels detected by Fluo-HPLC, $n=6$. k, I NMDA currents recording in the brain slices of Sardh ${ }^{-/-}$mice and formaldehyde-injected Sardh ${ }^{-/-}$ mice, $n=10-12$. $\mathbf{m}$ The effects of formaldehyde scavengers- L-cys $(300 \mu \mathrm{M})$ and $\mathrm{NaHSO}_{3}(300 \mu \mathrm{M})$ on the cell viability of the cultured hippocampal neurons detected by CCK-8 kit, $n=6$. Data are expressed as the mean \pm standard error (s.e.m.). ${ }^{\star \star \star} p<0.001 ;{ }^{\star \star \star *} p<0.0001$.

hippocampus impairments lead to memory deficits in children ${ }^{38}$. Thus, SARDH mutation-induced formaldehyde deficiency may be related with human cognitive impairments.

Formaldehyde deficiency induces amnesia in $\mathrm{Sardh}^{-/-}$mice. To further provide evidence that $S A R D H$ mutation directly impairs human cognition, we artificially made endogenous formaldehyde deficiency by knockout of Sardh gene in mice (Fig. 5f). The Sard $h^{-1-}$ mice exhibited body weight decline and low expression of SARDH in the hippocampus than control mice and were associated with no difference in motor ability than control (Supplementary Fig. 10). MWM tests also revealed deficits in spatial learning in Sardh ${ }^{-1-}$ mice compared to wild-types (WTs) and mutants receiving exogenous formaldehyde. After the 6-day MWM training, analyses of escape latency within trails for each day revealed that $S a r d h^{-1-}$ mice exhibited longer escape latencies than WT mice $(p<0.01)$; however, $\mathrm{Sardh}^{-1-}$ mice receiving formaldehyde injection exhibited a shorter escape latency than the mutated mice without formaldehyde treatment (Fig. $5 \mathrm{~g}, \mathrm{~h}$ ). Biochemical assays confirmed that Sardh knockout led to brain sarcosine and formaldehyde deficiency, while formaldehyde application increased brain formaldehyde from $\sim 150$ to $\sim 354 \mu \mathrm{M}$ (Fig. 5i, j). Consistent with memory decline, NMDA currents in the brain slices of Sardh ${ }^{-1-}$ mice were markedly lower than control mice (Fig. 5k, 1), indicating that endogenous formaldehyde deficiency causes memory deficits by suppressing NMDA currents.

We also observed the effects of formaldehyde scavengers on cell viability in the cultured hippocampal neurons at $24 \mathrm{~h}$. The results showed that formaldehyde scavengers, L-cys $(300 \mu \mathrm{M})$ and $\mathrm{NaHSO}_{3}(300 \mu \mathrm{M})$, markedly reduced cell viability (Fig. $\left.5 \mathrm{~m}\right)$. This result indicates that chemically scavenging formaldehyde induces formaldehyde deficiency and neuron death, which may contribute to hippocampal atrophy. 
Next, we used another chemical method to artificially reduce brain formaldehyde concentrations by intrahippocampally infusing $\mathrm{NaHSO}_{3}$ (a formaldehyde scavenger ${ }^{19}$ ) in healthy SD rats and again examined spatial learning in the MWM. Analyses of escape latency within each day revealed a significant effect on treatment day $4\left(\mathrm{~F}_{(1,18)}=3.68, p=0.003\right)$, day $5\left(\mathrm{~F}_{(1,18)}=4.73, p=0.001\right)$, and day $6\left(\mathrm{~F}_{(1,18)}=5.02, p=0.005\right)$. Post hoc analyses for days 4 , 5 and 6 showed that formaldehyde scavenger-injected mice exhibited significantly longer escape latencies than WT mice $(n=$ $8, p<0.01$ ) (Supplementary Fig. 11a). On day 7, formaldehyde scavenger-injected mice exhibited an obvious decline in both brain formaldehyde and the ability of spatial recall in the probe trial compared to untreated rats (Supplementary Fig. 11b, c). Taken together, both Sardh deletion and chemically scavenging formaldehyde indeed induce formaldehyde deficiency-related amnesia in mice.

\section{Discussion}

In this study, we found that spatial learning, HFS and glutamate stimulation elicited a rapid generation of active formaldehyde in rat hippocampus; the concentrations attained were sufficient to facilitate NMDA currents and enhanced LTP and memory formation. However, excess formaldehyde impaired memory in aldh2 $2^{-1-}$ mice and $\mathrm{AD}$ patients with $A L D H 2$ mutation by suppressing NMDA-R. In addition, brain formaldehyde deficiency in sarcosinemia children associated with $S A R D H$ mutation or in Sardh $h^{-1-}$ mice also led to cognitive deficits by reducing NMDA currents (Supplementary Fig. 12). These findings suggest that endogenous formaldehyde is a promising candidate memoryrelated molecule.

A previous study reported that urine formaldehyde levels were negatively correlated with cognitive function in $\mathrm{AD}$ patients ${ }^{8}$. Overexpression of semicarbazide-sensitive amine oxidase (SSAO, a serum formaldehyde-generating enzyme) and abnormally high formaldehyde has been found in APP/PS1 mice and autopsy hippocampus from AD patient $3^{39,40}$. Degradation of formaldehyde is mainly dependent on mitochondrial ALDH2 and cytoplasmic alcohol dehydrogenase $(\mathrm{ADH} 3 \text {, also named } \mathrm{FDH})^{23}$. FDH is specifically expressed in the hippocampus and cortex ${ }^{41}$. Knockout of FDH leads to visual memory deficits in Drosophila ${ }^{42}$. Under glutathione depletion in $\mathrm{AD}^{43}, \mathrm{ALDH} 2\left(K_{\mathrm{m}}\right.$ value $500 \mu \mathrm{M}$ for formaldehyde) plays a more important role in degrading pathological levels of formaldehyde ${ }^{44}$. Human ALDH2 mutation also increases the risk for late-onset $\mathrm{AD}^{45}$ and induces cognitive decline in diabetic patients ${ }^{14}$. In the current study, cognitive deficits were observed in formaldehyde-injected mice, aldh2 $2^{-l-}$ mice, and $\mathrm{AD}$ patients with $A L D H 2$ mutation. Excessive formaldehyde impaired NMDA-R signaling, thereby reducing the synaptoplastic changes underlying learning. Notably, memantine (an antagonist of NR2B) could alleviate dementia at the early stage of $\mathrm{AD}$, which may prevent formaldehyde-inactivated NMDA-R. However, high formaldehyde concentrations caused neuron death, contributing to the cortical atrophy observed in $\mathrm{AD}$. Use of a formaldehyde scavenger may be a potential therapeutic option for AD.

Formaldehyde deficiency and low intelligence quotient were observed in 11 pediatric sarcosinemia patients. These preschool children received insufficient clinical attention until they were tested by intelligence quotient screening tools and gene sequencing, mainly because sarcosinemia is a rare pediatric disease that is difficult to diagnose. Under physiological conditions, mitochondrial SARDH is an active formaldehyde-generating enzyme $^{18}$. However, the children harboring a $S A R D H$ mutation exhibited a decline in SARDH activity and formaldehyde generation. Injection of a formaldehyde scavenger or Sardh knockout in rodents induced formaldehyde deficiency as well as memory impairments. Endogenous formaldehyde also participates in onecarbon metabolism ${ }^{46}$ and DNA methylation ${ }^{6}$. Dynamic changes in brain DNA methylation are necessary for new memory formation ${ }^{47}$. Hence, formaldehyde deficiency could induce neuronal metabolic disruption, hippocampal atrophy, and ensuing cognitive dysfunction.

Application of formaldehyde precursor creatine has been found to improve memory in rats ${ }^{48}$. Especially, oral supplementation of creatine significantly enhances human working memory ${ }^{49}$. Another precursor, sarcosine has been believed to enhance LTP formation in vitro ${ }^{50}$. In this study, we found that supplementation of formaldehyde precursors, creatine and sarcosine, could facilitate the formation of both LTP and memory, respectively. Application of L-cys (a formaldehyde scavenger) could reverse excessive formaldehyde-induced memory deficits. Interestingly, supplementation of a moderate amount of formaldehyde rescued formaldehyde deficiency-induced cognitive decline. Therefore, targeting formaldehyde and its metabolizing enzymes may be a promising therapeutic approach for preventing or treating cognitive disorders. In conclusion, our findings suggest that the primary small molecule, endogenous formaldehyde, regulates memory formation.

\section{Methods}

Clinical survey of sarcosinemia and dementia patients. The clinical study was registered at the Chinese Clinical Trial Registry (http://www.chictr.org/cn, Unique Identifier: ChiCTR-OOC-14005576) and was conducted between October 2013 and July 2015. We recruited participants from Beijing geriatric hospital and Peking University Third Hospital, China. Participants who refused to provide blood or urine samples, had a life-threatening illness, or were unable to participate in the assessment were excluded from the entire survey. The mean age of the 158 individuals (71 elderly patients with Alzheimer's disease, AD and 87 age-matched controls) was $72.61 \pm 3.19$ years, and cognitive function was assessed using the Mini-Mental State Examination (MMSE) ${ }^{8}$ (Supplementary Table 1). The brains were scanned by computer tomography (CT). The mean age of the 11 preschool children with sarcosinemia and 31 age-match controls from Beijing Children's

Hospital, Beijing BoAi Hospital, and Sichuan Provincial Hospital for Women and Children was $6.18 \pm 1.69$ years, and human intelligence quotient was examined by using the Wechsler Intelligence Scale for Children (WISC) ${ }^{51}$ (Supplementary Table 3). The brains were examined by the magnetic resonance imaging (MRI) and Fluorine $^{18}$ - fluorodeoxyglucose positron emission tomography/computed tomography $\left({ }^{18} \mathrm{~F}\right.$-FDG PET/CT). Morning urine and serum from above participants were collected for measuring sarcosine and formaldehyde concentrations. The venous blood was used to enzyme activity analysis and gene sequencing. Informed consent was obtained from each participant either directly or from his or her guardian before participation. Ethical approval for the clinical investigations was obtained from the Clinical Ethics Committee at the Capital Medical University, China.

Generation of Sardh ${ }^{-/}$mice. All protocols involving the use of animals were conducted in accordance with the Biological Research Ethics Committee, Capital Medical University, China. The adult male C56BL/6 mice at two-month-old age were housed in a temperature-controlled room under a 12-h light-12-h dark circadian cycle with access to water and food ad libitum. Mouse sarcosine dehydrogenase (SARDH: Gene ID: 192166) CRISPR/Cas9 KO plasmid (sc-407703) was purchased from Santa Cruz Biotechnology, USA. Further, Sardh ${ }^{-l-}$ mice were made by the Institute of Medical Experimental Animals, Chinese Academy of Medical Sciences as shown in Fig. 5f. Sardh ${ }^{-1-}$ mice were identified by using fluorescent histochemistry of SARDH (antibody of SARDH, SAB130499, 1:500, Sigma-Aldrich, USA), and by PCR with the DNA primers, F1: 5'-TGGCTCCACAAAACTCATGTC-3'; R1: 5'-GAGCCTCTGGATGGCTGAAG', to generate a 84 bp product (Supplementary Fig. 10). The SARDH activity in mice was analyzed by mouse SARDH kit.

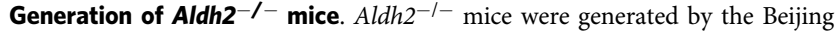
Biocytogen Co., Ltd, China and described in Fig. 4a. The Aldh2 gene in the mice was identified by PCR with the DNA primers, F1: 5'-GGAAGATGTGGACAAGGCAG-3'; R1: 5'-ATGCCACTTTGTCCA CATCC-3', to generate a 560 bp product. The ALDH2 activity was analyzed by mouse ALDH2 kit.

Chemicals and reagents. Unless otherwise stated, all chemicals and reagents were obtained from Sigma-Aldrich. 
Rotarod test. The accelerating rotarod apparatus (AccuScan Instruments, Columbus, OH, USA) consisted of a suspended rod that accelerates at a constant rate, from 4 to $70 \mathrm{rpm}$ in $300 \mathrm{~s}$. At each day of training, mice were trained on the rotarod throughout a session of ten trials. A trial ends when the mouse falls off the rod or after reaching $300 \mathrm{~s}$. Time was recorded for each trial. A resting time of $180 \mathrm{~s}$ was allowed between each trial.

\section{Intrahippocampal microinjection and Morris water maze test. Stereotaxic} surgery and intrahippocampal microinjection were conducted as described in previous report ${ }^{52}$. Briefly, the male adult Sprague-Dawley (SD) rats at 2 -monthold age were implanted bilaterally with stainless steel guide cannula $(-3.80 \mathrm{~mm}$ posterior to bregma; $2.2 \mathrm{~mm}$ left and right to the sagittal suture; $-3.2 \mathrm{~mm}$ ventral to the skull surface) in the CA1 area of the hippocampus. Stainless steel styles (23gauge) were inserted into the guide cannulae to keep them free of debris. After 7 days' recovery, these SD rats were randomly divided into different groups $(n=6$ -10 , each group): Control group (normal saline); formaldehyde groups $(450 \mu \mathrm{M})$; formaldehyde scavenger- $\mathrm{NaHSO}_{3}$ group $\left(200 \mu \mathrm{M}^{53}\right)$. All injections were $5 \mu \mathrm{L}$ in volume and slowly applied $(5 \mathrm{~min}$ ) and performed $30 \mathrm{~min}$ before Morris maze test. The behaviors of spatial memory in transgenic mice or SD rats were assessed by MWM as described previously ${ }^{54,55}$.

Open-field novel object recognition (NOR) task. The NOR task consisted of 3 consecutive days of testing per trial; habituation, training with two identical objects, and testing with one familiar and one novel object. On the testing day, animals were allowed to explore the objects until they accumulated $30 \mathrm{~s}$ of total object exploration time (exploration was recorded when the nose of the mouse was within approximately $1 \mathrm{~cm}$ of the object). This was done rather than using a set exposure time in the test environment in order to account for any variability in movement and exploration that may occur between mice. Two measures of behavior were assessed: frequency of visits to the objects, and the time spent exploring each object. From the latter measure the discrimination index (difference in time exploring the novel and familiar object, divided by total exploration time) and the ratio of time spent with the novel object in relation to the familiar object were calculated.

Intracerebroventricular injection and LTP recording. Intracerebroventricular injection (i.c.v.) performed $30 \mathrm{~min}$ before high-frequency stimulation (HFS), hippocampal long-term potentiation (LTP) or late long-term potentiation (L-LTP) recordings from the Cornu Ammonis 1 (CA1) to Schaffer collateral pathway of $\mathrm{CA} 3$ in SD rats were performed as previously reported ${ }^{56}$.

Hippocampal neuron culture. We prepared primary hippocampal neuron culture from 18-day-old embryos as described previously ${ }^{57}$. Then the medicines were coincubated or transfected into the cultured neurons. The reagents including: Methoxyacetic acid (MA, $200 \mu \mathrm{M}$, \#08485, Sigma-Aldrich, USA), a competitive inhibitor of SARDH, which can inhibit sarcosine degradation ${ }^{58}$.

In vitro multiple action potentials recording. Dissociated cell cultures of hippocampal neurons from 1- to 2-day-old Sprague-Dawley rats were prepared, and the bath and electrode solutions were used as previously described ${ }^{59,60}$, except that the bath solution was not oxygenated. Recordings of multiple action potentials were done with two patch-clamp amplifiers (2 Axopatch 200B or 2 Axopatch 1D; Axon, Foster City, California). Signals were filtered at $5 \mathrm{kHZ}$ using amplifier circuitry and stored on a VCR. Data were acquired using Axoscope 1.0 or pClamp 6.0 and analyzed using pClamp 6.0 software (Axon). Recordings were only made on neurons with an initial resting membrane potential $\leq-50 \mathrm{mV}$. The multiple action potentials were recorded as described previously ${ }^{61}$

Hippocampal slice preparation. Hippocampal slices were prepared as described previously ${ }^{62}$. Following diethyl ether anesthesia, animals were decapitated, the brain was removed and cooled in artificial cerebrospinal fluid (ACSF, composition in mM: $\mathrm{NaCl} 134, \mathrm{KCl} 5, \mathrm{NaH}_{2} \mathrm{PO}_{4} \cdot 2 \mathrm{H}_{2} \mathrm{O} 1.5, \mathrm{MgSO}_{4} 2, \mathrm{CaCl}_{2} 2, \mathrm{NaHCO}_{3} 25$, Glucose 10 , saturated with $95 \% \mathrm{O}_{2} / 5 \% \mathrm{CO}_{2}$ with $\mathrm{pH}=7.4$ ) for $2 \mathrm{~min}$. Then, the hippocampi were sliced to a thickness of $350-400 \mu \mathrm{m}$, using a vibrating tissue slicer (Vibratome 3000, Virratome, America). Slices were placed in a storage chamber filled with ACSF and kept at least for $1 \mathrm{~h}$ at room temperature $\left(\sim 25^{\circ} \mathrm{C}\right)$. Before recording, the slices were individually transferred to a recording chamber and continuously perfused with oxygenated standard external solution at a rate of $2 \mathrm{~mL} / \mathrm{min}$ during experiment, which contained (in mmol/L): $130 \mathrm{NaCl}, 5.4 \mathrm{KCl}$, $1 \mathrm{MgCl}_{2}, 2 \mathrm{CaCl}_{2}, 10$ HEPES, 10 glucose, and the $\mathrm{pH}$ was adjusted to 7.4 with Trisbase. Both external and internal solutions were made up using salts of analytical grade in twice-distilled deionized water.

In vitro recording NMDA currents in hippocampal slices. Whole-cell recordings were obtained, using an MultiClamp 700B Amplifier (Molecular Devices, Union City, $\mathrm{CA})$ as described previously ${ }^{63}$. Slices were superfused with the above external solution. Experiments were performed at $\sim 25^{\circ} \mathrm{C}$, with the temperature maintained by an in-line heating device (Warner Instruments, Hamden, USA). Patch pipettes $(2.0-3.5 \mathrm{M} \Omega$ ) were filled with an internal solution containing the following (in $\mathrm{mM}$ ):
$\mathrm{Cs}^{+}$methanesulfonate 135, $\mathrm{NaCl} 8$, HEPES 10, Cs-BAPTA 10, Mg-ATP 4, Na-GTP 0.4 , verapamil 0.2 (voltage clamp experiments). NMDAR currents were recorded in the presence of D-serine $(10 \mu \mathrm{M})$, NBQX $(10 \mu \mathrm{M})$, TTX $(0.5 \mu \mathrm{M})$, and picrotoxin $(100 \mu \mathrm{M})$. The altered protocol was only that the holding voltage $(+40 \mathrm{mV})$ was changed to hold at $-60 \mathrm{mV}$. Flow-pipe solutions were continuously bubbled with $95 \% \mathrm{O}_{2}, 5 \% \mathrm{CO}_{2}$

Site-directed mutagenesis of NR1 and NR2B plasmids. The plasmids of pcDNA3.1-GFP-NR1a and pcDNA3.1-NR2B for NMDA-induced intracellular $\mathrm{Ca}^{2+}$ influx in the cultured $\mathrm{CHO}$ cells were donated from the lab of Dr. Jianhong Luo, Zhejiang University, China ${ }^{64}$. The wild-type plasmids of Grin 1 and Grin2b were purchased from OriGene Technologies, Rockville, Maryland, USA. Deletion of sequences of ATD of NR2B, the single-site mutation of C79S of NR1, K79A of $\mathrm{NR} 2 \mathrm{~B}$, or C232A of NR2B, according to the method of previous reports 30,65 , were carried out by Beijing OriGene Technology Co., Ltd, Beijing, China. The DNA sequences of wild-type and mutants of NR1/NR2B subunit were identified by ABI 3730XL DNA analyzer (\#3730XL, Thermo Fisher Scientific, USA).

Transfection protocol. Chinese hamster ovary cells $(\mathrm{CHO})$ were grown in Ham's F-12 nutrient medium with $10 \%$ fetal bovine serum and $1 \mathrm{mM}$ glutamine and passaged at a 1:10 dilution when $80 \%$ confluent, approximately every 2 days. $\mathrm{CHO}$ cells were seeded at $3 \times 10^{5}$ cells per well in six-well plates approximately $24 \mathrm{~h}$ before transfection with $1.3 \mathrm{mg}$ of total DNA and $6 \mathrm{~mL}$ of Lipofectamine (GIBCO/ $\mathrm{BRL}$ ) in $1 \mathrm{~mL}$ of serum-free $\mathrm{CHO}$ media per $35-\mathrm{mm}$ dish. The ratio of plasmids to total DNA was 1:4, and the ratio of NR1a to NR2B was 1:3. After a 4- to 5-h incubation at $37^{\circ} \mathrm{C}$, cells were refed with $\mathrm{CHO}$ medium containing $1 \mathrm{mM} \mathrm{5,7-}$ dichlorokynurenic acid to prevent cell death. Cells were used for intracellular $\mathrm{Ca}^{2+}$ imaging or recording $40-50 \mathrm{~h}$ after transfection.

Intracellular $\mathrm{Ca}^{2+}$ imaged by laser confocal. The $\left[\mathrm{Ca}^{2+} i\right]$ imaging in the $\mathrm{CHO}$ cells was used with Fluo- 3 of $\mathrm{Ca}^{2+}$ probe. Another $\mathrm{Ca}^{2+}$ probe- Fluo- 4 was used to the $\left[\mathrm{Ca}^{2+} i\right]$ imaging in the cultured hippocampal neurons described as previously ${ }^{66}$.

NMDA currents recordings by patch-clamp. Recordings were performed at $\sim 25^{\circ} \mathrm{C}$ on outside-out patches with $10-15 \mathrm{M} \Omega$ electrodes in the transfected $\mathrm{CHO}$ cells or hippocampal neurons. The extracellular solution contained $150 \mathrm{mM} \mathrm{NaCl}$ $2.8 \mathrm{mM} \mathrm{KCl}, 1.0 \mathrm{mM} \mathrm{CaCl}_{2}, 10 \mathrm{mM}$ Hepes, $0.01 \mathrm{mM}$ glycine, $\mathrm{pH}$ adjusted to 7.2 with $0.3 \mathrm{~N} \mathrm{NaOH}$. The pipette solution contained $140 \mathrm{mM}$ CsF, $10 \mathrm{mM}$ EGTA, $1.0 \mathrm{mM} \mathrm{CaCl} 2,10 \mathrm{mM}$ Hepes, $\mathrm{pH}$ adjusted to 7.2 with $\mathrm{CsOH}$. Recordings were made at $-60 \mathrm{mV}$ and $200 \mu \mathrm{M} \mathrm{NMDA}, 100 \mu \mathrm{M}$ Ifenprodil (an antagonist of NR2B), and formaldehyde $(0,50,150,300$ and $450 \mu \mathrm{M})$ were applied to the patch by complete bath.

Detection of formaldehyde with formaldehyde kit or Fluo-HPLC. Formaldehyde in the medium from cultured hippocampal neurons was incubated with different medicines was quantified by high-performance liquid chromatography with fluorescence detection (Fluo-HPLC) as described previously ${ }^{20}$. Formaldehyde concentrations in other samples were analyzed by DFOR-100 formaldehyde kit in accordance with the manufacturer's instructions (BioAssay Systems, Hayward, CA, USA)

Detection of sarcosine with rat sarcosine kit or HPLC. The sarcosine in the medium from cultures was collected and detected by Fluo-HPLC ${ }^{67}$. Sarcosine concentrations in other samples were analyzed by sarcosine Fluorimetric Assay Kit according to the manufacturer's instructions (ABIN411704, 4A Biotech Co., Ltd, China).

Molecular simulations of formaldehyde-binding with NR1/NR2B. The threedimensional (3D) crystal structure of Glun1 and Glun2b in Complex with Ifenprodil (PDB ID: 3QEL) was downloaded for free (Protein Data Bank, https://www. rcsb.org/structure/3QEL). Crystal structure of Glun1a/Glun2b of Nmda Receptor Ion Channel (PDB ID: 4PE5) was downloaded (Protein Data Bank, https://www. rcsb.org/structure/4PE5). The possible binding site between formaldehyde and NR1/NR2B was analyzed by using the PyMOL 1.7 software, which can be downloaded for free (http://sourceforge.net/projects/pymol/).

Statistics and reproducibility. All data were tested for normality by the Kolmogorov-Smirnov test. When data were normally distributed, the statistical significance of differences was assessed with the unpaired $t$ test and one- or two-way ANOVA, analyzed by Tukey post hoc. When data were not normally distributed, the statistical significance of differences was judged on the basis of $p$ values with the Mann-Whitney $U$ test and analyzed by IBM SPSS v19.0 (SPSS Inc., Chicago, IL, USA).

Human serum biochemical index was assessed using Student's unpaired $t$ test. Gender of participants was assessed using the chi-squared test. 
Correlations between urine formaldehyde levels and MMSE or WISC scores were assessed using Pearson correlation coefficient, both without adjustment, then accounting for sex and age. These data were analyzed by IBM SPSS v19.0.

Mice serum biochemical index was assessed using Student's unpaired $t$ test. The spatial memory behaviors in MWM of mice were analyzed by Tukey post hoc with repeated measures ANOVA.

The changes in the response amplitudes of LTP were analyzed using mixed design ANOVAs.

Statistical significance was set to $p<0.05$. Analyses were performed using the GraphPad Prism 6 software (GraphPad PRISM software, version 6.01; GraphPad Software, Inc, La Jolla, CA).

Reporting summary. Further information on research design is available in the Nature Research Reporting Summary linked to this article.

\section{Data availability}

All data and biological materials generated in this study are available from the corresponding author upon request. The reporting summary for this article is available as a Supplementary raw file. The source data underlying Fig. 3 are provided in Supplementary Figs. 2-6. The information of SARDH mutants is provided in Supplementary Fig. 9 .

Received: 12 July 2019; Accepted: 4 November 2019; Published online: 29 November 2019

\section{References}

1. Canuto, V. M. et al. The young Sun and the atmosphere and photochemistry of the early Earth. Nature 305, 281-286 (1983).

2. Pinto, J. P., Gladstone, G. R. \& Yung, Y. L. Photochemical production of formaldehyde in Earth's primitive atmosphere. Science 210, 183-185 (1980).

3. Robertson, M. P. \& Miller, S. L. An efficient prebiotic synthesis is of cytosine and uracil. Nature 375, 772-774 (1995).

4. Lu, Z. et al. Effect of inhaled formaldehyde on learning and memory of mice. Indoor Air 18, 77-83 (2008).

5. Kilburn, K. H., Warshaw, R. \& Thornton, J. C. Formaldehyde impairs memory, equilibrium, and dexterity in histology technicians: effects which persist for days after exposure. Arch. Environ. Health 42, 117-120 (1987).

6. Kalasz, H. Biological role of formaldehyde, and cycles related to methylation, demethylation, and formaldehyde production. Mini Rev. Med. Chem. 3, 175-192 (2003).

7. Heck, H. D., White, E. \& Casanova-Schmitz, M. Determination of formaldehyde in biological tissues by gas chromatography/mass spectrometry. Biomed. Mass Spectrom. 9, 347-353 (1982).

8. Tong, Z. Q. et al. Urine formaldehyde level is inversely correlated to mini mental state examination scores in senile dementia. Neurobiol. Aging 32, 31-42 (2011)

9. Chi, Y. N. et al. Formaldehyde increases intracellular calcium concentration in primary cultured hippocampal neurons partly through NMDA receptors and T-type calcium channels. Neurosci. Bull. 28, 715-722 (2012).

10. Coderre, T. J. \& Melzack, R. The role of NMDA receptor-operated calcium channels in persistent nociception after formalin-induced tissue injury. $J$. Neurosci. 12, 3671-3675 (1992).

11. Shimizu, E., Tang, Y. P., Rampon, C. \& Tsien, J. Z. NMDA receptordependent synaptic reinforcement as a crucial process for memory consolidation. Science 290, 1170-1174 (2000).

12. Beinhoff, U., Tumani, H. \& Riepe, M. W. Applying new research criteria for diagnosis of early Alzheimer's disease: sex and intelligence matter. Int. J. Alzheimers Dis. https://doi.org/10.4061/2009/638145 (2009).

13. Wang, B. et al. The association of mitochondrial aldehyde dehydrogenase gene (ALDH2) polymorphism with susceptibility to late-onset alzheimer's disease in Chinese. J. Neurol. Sci. 268, 172-175 (2008).

14. Tan, T. et al. Formaldehyde induces diabetes-associated cognitive impairments. FASEB J. 32, 3669-3679 (2018).

15. Ohsawa, I., Nishimaki, K. \& Murakami, Y. Age-dependent neurodegeneration accompanying memory loss in transgenic mice defective in mitochondrial aldehyde dehydrogenase 2 activity. J. Neurosci. 28, 6239-6249 (2008).

16. Benarrosh, A. et al. A young adult with sarcosinemia. No benefit from long duration treatment with memantine. JIMD Rep. 9, 93-96 (2013).

17. Lee, S. Y., Chan, K., Chan, A. Y. \& Lai, C. K. A report of two families with sarcosinaemia in Hong Kong and revisiting the pathogenetic potential of hypersarcosinaemia. Ann. Acad. Med. Singap. 35, 582-584 (2006).
18. Scott, C. R., Clark, S. H., Teng, C. C. \& Swedberg, K. R. Clinical and cellular studies of sarcosinemia. J. Pediatr. 77, 805-811 (1970).

19. Tang, Y. et al. Development of a two-photon fluorescent probe for imaging of endogenous formaldehyde in living tissues. Angew. Chem. Int. Ed. Engl. 55, 3356-3359 (2016).

20. Luo, W., Li, H., Zhang, Y. \& Ang, C. Y. Determination of formaldehyde in blood plasma by high-performance liquid chromatography with fluorescence detection. J. Chromatogr. B Biomed. Sci. Appl. 753, 253-257 (2001).

21. Bashir, Z. I. et al. Induction of LTP in the hippocampus needs synaptic activation of glutamate metabotropic receptors. Nature 363, 347-350 (1993).

22. Xu, A., Tang, Y. \& Lin, W. Y. Development of a mitochondrial-targeted twophoton fluorescence turn-on probe for formaldehyde and its bio-imaging applications in living cells and tissues. N. J. Chem. 42, 8325-8329 (2018).

23. Teng, S. et al. The formaldehyde metabolic detoxification enzyme systems and molecular cytotoxic mechanism in isolated rat hepatocytes. Chem. Biol. Interact. 130-132, 285-296 (2001).

24. Brodin, L., Bakeeva, L. \& Shupliakov, O. Presynaptic mitochondria and the temporal pattern of neurotransmitter release. Philos. Trans. R. Soc. Lond. B Biol. Sci. 354, 365-372 (1999).

25. Cao, X. et al. In vivo imaging reveals mitophagy independence in the maintenance of axonal mitochondria during normal aging. Aging Cell 16, $1180-1190$ (2017).

26. Yasuhara, M. et al. Continuous-flow enzymic determination of creatine in urine. Clin. Chem. 27, 1888-1891 (1981).

27. Tong, Z. et al. Aging-associated excess formaldehyde leads to spatial memory deficits. Sci. Rep. 3, 1807 (2013).

28. Monyer, $\mathrm{H}$. et al. Heteromeric NMDA receptors: molecular and functional distinction of subtypes. Science 256, 1217-1221 (1992).

29. Tabone, C. J. \& Ramaswami, M. Is NMDA receptor-coincidence detection required for learning and memory? Neuron 74, 767-769 (2012).

30. Sirrieh, R. E., MacLean, D. M. \& Jayaraman, V. A conserved structural mechanism of NMDA receptor inhibition: a comparison of ifenprodil and zinc. J. Gen. Physiol. 146, 173-181 (2015).

31. Mony, L. et al. Structural basis of NR2B-selective antagonist recognition by $N$ methyl-D-aspartate receptors. Mol. Pharm. 75, 60-74 (2009).

32. Mackenzie, C. G. \& Harris, J. N-formylcysteine synthesis in mitochondria from formaldehyde and L-cysteine via thiazolidinecarboxylic acid. J. Biol. Chem. 227, 393-406 (1957).

33. Lee, C. H. \& Gouaux, E. Amino terminal domains of the NMDA receptor are organized as local heterodimers. PLoS ONE 6, e19180 (2011).

34. Karakas, E. \& Furukawa, H. Crystal structure of a heterotetrameric NMDA receptor ion channel. Science 344, 992-997 (2014).

35. Metz, B. et al. Identification of formaldehyde-induced modifications in proteins: reactions with insulin. Bioconjug. Chem. 17, 815-822 (2006)

36. Toews, J., Rogalski, J. C., Clark, T. J. \& Kast, J. Mass spectrometric identification of formaldehyde-induced peptide modifications under in vivo protein cross-linking conditions. Anal. Chim. Acta 618, 168-183 (2008).

37. Donders, J. \& Janke, K. Criterion validity of the Wechsler Intelligence Scale for Children-Fourth Edition after pediatric traumatic brain injury. J. Int. Neuropsychol. Soc. 14, 651-655 (2008)

38. Molet, J. et al. MRI uncovers disrupted hippocampal microstructure that underlies memory impairments after early-life adversity. Hippocampus 26, 1618-1632 (2016).

39. Ferrer, I., Lizcano, J. M., Hernandez, M. \& Unzeta, M. Overexpression of semicarbazide sensitive amine oxidase in the cerebral blood vessels in patients with Alzheimer's disease and cerebral autosomal dominant arteriopathy with subcortical infarcts and leukoencephalopathy. Neurosci. Lett. 321, 21-24 (2002).

40. Rizak, J. D., Ma, Y. \& Hu, X. Is formaldehyde the missing link in AD pathology? The differential aggregation of amyloid-beta with APOE isoforms in vitro. Curr. Alzheimer Res. 11, 461-468 (2014)

41. Galter, D., Carmine, A., Buervenich, S., Duester, G. \& Olson, L. Distribution of class I, III and IV alcohol dehydrogenase mRNAs in the adult rat, mouse and human brain. Eur. J. Biochem. 270, 1316-1326 (2003).

42. Hou, Q. et al. Nitric oxide metabolism controlled by formaldehyde dehydrogenase (fdh, homolog of mammalian GSNOR) plays a crucial role in visual pattern memory in Drosophila. Nitric Oxide 24, 17-24 (2011).

43. Saharan, S. \& Mandal, P. K. The emerging role of glutathione in Alzheimer's disease. J. Alzheimers Dis. 40, 519-529 (2014).

44. Dicker, E. \& Cederbaum, A. I. Inhibition of the low-Km mitochondrial aldehyde dehydrogenase by diethyl maleate and phorone in vivo and in vitro. Implications for formaldehyde metabolism. Biochem. J. 240, 821-827 (1986).

45. Kamino, K. et al. Deficiency in mitochondrial aldehyde dehydrogenase increases the risk for late-onset Alzheimer's disease in the Japanese population. Biochem Biophys. Res. Commun. 273, 192-196 (2000).

46. Burgos-Barragan, G. et al. Mammals divert endogenous genotoxic formaldehyde into one-carbon metabolism. Nature 548, 549-554 (2017). 
47. Miller, C. A. \& Sweatt, J. D. Covalent modification of DNA regulates memory formation. Neuron 53, 857-869 (2007).

48. Souza, M. A. et al. Involvement of hippocampal CAMKII/CREB signaling in the spatial memory retention induced by creatine. Amino Acids 43, 2491-2503 (2012).

49. Rae, C., Digney, A. L., McEwan, S. R. \& Bates, T. C. Oral creatine monohydrate supplementation improves brain performance: a doubleblind, placebo-controlled, cross-over trial. Proc. Biol. Sci. 270, 2147-2150 (2003).

50. Martina, M. et al. Glycine transporter type 1 blockade changes NMDA receptor-mediated responses and LTP in hippocampal CA1 pyramidal cells by altering extracellular glycine levels. J. Physiol. 557, 489-500 (2004).

51. Caruso, J. C., Witkiewitz, K., Youngstrom, E. A. \& Glutting, J. J. The frequency of reliable component difference scores for the Wechsler Intelligence Scale for Children-Third edition in two samples. Psychol. Assess. 13, 543-548 (2001).

52. Schott, P. A., Bjelke, B. \& Ogren, S. O. Time-dependent effects of intrahippocampal galanin on spatial learning. Relationship to distribution and kinetics. Ann. N.Y. Acad. Sci. 863, 454-456 (1998).

53. Tang, Y. et al. Lysosome-targeted turn-on fluorescent probe for endogenous formaldehyde in living cells. Anal. Chem. 88, 9359-9363 (2016).

54. Morris, R. Developments of a water-maze procedure for studying spatial learning in the rat. J. Neurosci. Methods 11, 47-60 (1984).

55. Tong, Z. et al. Age-related formaldehyde interferes with DNA methyltransferase function, causing memory loss in Alzheimer's disease. Neurobiol. Aging 36, 100-110 (2015).

56. Tong, Z. et al. Accumulated hippocampal formaldehyde induces agedependent memory decline. Age (Dordr.) 35, 583-596 (2013).

57. Nie, C. L. et al. Amyloid-like aggregates of neuronal tau induced by formaldehyde promote apoptosis of neuronal cells. BMC Neurosci. 8, 9 (2007).

58. Porter, D. H., Cook, R. J. \& Wagner, C. Enzymatic properties of dimethylglycine dehydrogenase and sarcosine dehydrogenase from rat liver Arch. Biochem. Biophys. 243, 396-407 (1985).

59. Arancio, O., Kandel, E. R. \& Hawkins, R. D. Activity-dependent long-term enhancement of transmitter release by presynaptic $3^{\prime}, 5^{\prime}$-cyclic GMP in cultured hippocampal neurons. Nature 376, 74-80 (1995).

60. Arancio, O. et al. Nitric oxide acts directly in the presynaptic neuron to produce long-term potentiation in cultured hippocampal neurons. Cell 87, 1025-1035 (1996).

61. Abizaid, A. et al. Ghrelin modulates the activity and synaptic input organization of midbrain dopamine neurons while promoting appetite. J. Clin. Invest. 116, 3229-3239 (2006).

62. Tan, T. et al. Repetitive transcranial magnetic stimulation increases excitability of hippocampal CA1 pyramidal neurons. Brain Res. 1520, 23-35 (2013).

63. Herman, M. A. \& Jahr, C. E. Extracellular glutamate concentration in hippocampal slice. J. Neurosci. 27, 9736-9741 (2007).

64. Yang, W. et al. A three amino acid tail following the TM4 region of the Nmethyl-D-aspartate receptor (NR) 2 subunits is sufficient to overcome endoplasmic reticulum retention of NR1-1a subunit. J. Biol. Chem. 282, 9269-9278 (2007).

65. Lee, C. H. et al. NMDA receptor structures reveal subunit arrangement and pore architecture. Nature 511, 191-197 (2014).

66. Tong, Z. Q. et al. Tumor tissue-derived formaldehyde and acidic microenvironment synergistically induce bone cancer pain. PLOS ONE $\mathbf{5}$ e10234 (2010).
67. Chung, T. C., Li, C., Kou, H. S. \& Wu, H. L. High-performance liquid chromatographic analysis of sarcosine as a fluorescent levofloxacin derivative. J. Chromatogr. Sci. 53, 1310-1315 (2015).

\section{Acknowledgements}

This work was supported by grants from the Chinese Institute for Brain Research, Beijing (CIBR, Beijing) (Z181100001518004), NSFC (61625102, 61827810 and 81571044) and HTRDC (2016YFC1305903, and 2016YFC1306302), 973 Program, 2015CB856402, the Beijing Natural Science Foundation of China (Grant No. 7172022); the Scientific Research Common Program of Beijing Municipal Commission of Education (KM201510025014); and the Major Projects Fund of Beijing Institute for Brain Disorders (ZD2015-08), the startup fund of Advanced Innovation Center for Human Brain Protection (1172120205).

\section{Author contributions}

Z.T. designed the study; L.A., T.T., Y.T., J.Y., D.C., R.W., A.W., X.F., Y.D., X.W., Y.Y., S.Z., W.W., S.B., X.Y. and R.H. performed the study; H.H., X.C., W.L. and Z.T. analyzed the results; L.A., T.T., X.C. and Z.T. wrote the paper together. All authors have read and approved the final version of the manuscript.

\section{Competing interests}

The authors declare no competing interests.

\section{Additional information}

Supplementary information is available for this paper at https://doi.org/10.1038/s42003019-0694-x.

Correspondence and requests for materials should be addressed to Z.T

Reprints and permission information is available at http://www.nature.com/reprints

Publisher's note Springer Nature remains neutral with regard to jurisdictional claims in published maps and institutional affiliations.

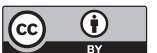

Open Access This article is licensed under a Creative Commons Attribution 4.0 International License, which permits use, sharing, adaptation, distribution and reproduction in any medium or format, as long as you give appropriate credit to the original author(s) and the source, provide a link to the Creative Commons license, and indicate if changes were made. The images or other third party material in this article are included in the article's Creative Commons license, unless indicated otherwise in a credit line to the material. If material is not included in the article's Creative Commons license and your intended use is not permitted by statutory regulation or exceeds the permitted use, you will need to obtain permission directly from the copyright holder. To view a copy of this license, visit http://creativecommons.org/ licenses/by/4.0/.

(c) The Author(s) 2019 